\title{
Leader corruption depends on power and testosterone
}

\author{
Samuel Bendahan ${ }^{1,2}$ \\ Christian Zehnder ${ }^{1}$ \\ François P. Pralong ${ }^{3}$ \\ John Antonakis ${ }^{1 *}$
}

In press

The Leadership Quarterly

\begin{abstract}
${ }^{1}$ Faculty of Business and Economics, Department of Organizational Behavior, University of Lausanne, 1015 Switzerland. ${ }^{2}$ Laboratory of Behavioral Genetics, Brain Mind Institute, École Polytechnique Fédérale de Lausanne (EPFL), CH-1015 Lausanne, Switzerland; ${ }^{3}$ Service of Endocrinology, Diabetology and Metabolism, University Hospital and Faculty of Biology and Medicine, University of Lausanne, 1015 Switzerland.
\end{abstract}

*To whom correspondence should be addressed. E-mail: john.antonakis@ unil.ch; Telephone +41 216923438

Acknowledgements: We are grateful to Alice Eagly, Armin Falk, Mark van Vugt, and Michael Zyphur for helpful comments we received on previous versions of this manuscript.

A podcast on our article, which can be used as a pedagogical tool is available here: https://www.youtube.com/watch?v=JoLLPNZLBAo 


\title{
Leader corruption depends on power and testosterone
}

\begin{abstract}
We used incentivized experimental games to manipulate leader power - the number of followers and the discretion leaders had to enforce their will. Leaders had complete autonomy in deciding payouts to themselves and their followers. Although leaders could make prosocial decisions to benefit the public good they could also abuse their power by invoking antisocial decisions, which reduced the total payouts to the group but increased leader's earnings. In Study $1(N=478)$, we found that both amount of followers and discretionary choices independently predicted leader corruption. In Study $2(N=240)$, we examined how power and individual differences (e.g., personality, hormones) affected leader corruption over time; power interacted with testosterone in predicting corruption, which was highest when leader power and baseline testosterone were both high. Honesty predicted initial level of leader antisocial decisions; however, honesty did not shield leaders from the corruptive effect of power.
\end{abstract}

Keywords: power; leadership; corruption; testosterone; dictator game. 
More than 100 years ago, Acton suggested: "Power tends to corrupt, and absolute power corrupts absolutely" (Acton \& Himmelfarb, 1948, pp. 335-336). Acton's statement is intuitively appealing and has become an often-used quote in academia and practice. It is clear why: Leaders wield power and can have important consequences on outcomes whether in micro- or macroorganizational settings (Flynn, Gruenfeld, Molm, \& Polzer, 2011; House, Spangler, \& Woycke, 1991; Jones \& Olken, 2005; Judge \& Piccolo, 2004; Lowe, Kroeck, \& Sivasubramaniam, 1996).The hierarchical nature of organizations, rooted in status and power differences (Magee \& Galinsky, 2008), results in political tensions, power asymmetries, and conflicting interests (Flynn, et al., 2011) These dynamics raise an important question that we sought to answer in this study: Do those with power use it in ways that serves the greater good or do they succumb to its corruptive effects?

From antiquity (Plato \& Jowett, 1901) to today (Anand, Ashforth, \& Joshi, 2005; Brief, Buttram, \& Dukerich, 2001; Manz, Anand, Joshi, \& Manz, 2008; Sherman, 1980), scholars have shown increased interest in understanding the causes of corruption and how it permeates organizations, as well as the detrimental effect of corruption on economies (Mauro, 1995). Given the importance of leaders as creators or shapers of organizational culture (Schein, 1990, 1992), and that unethical behaviors have spillover effects (Gino, Ayal, \& Ariely, 2009), it is critical to know whether power does indeed corrupt.

Basic research findings at the individual leader level thus have important policy implications for institutions, which would want to ensure that they have the necessary safeguards so that leaders use power in prosocial ways. That power may corrupt is indeed possible; however, it is also equally possible that those who are corrupt "at heart" may seek power. Thus, observing corruption in field settings may confound findings (i.e., because of endogeneity see Antonakis, Bendahan, Jacquart, \& Lalive, 2010). To isolate power's effect on corruption using observational 
data one would have to tease-out the selection effects (cf. Heckman, 1979) or correct for other sources of endogeneity bias — which is difficult to accomplish in practice — or to experimentally manipulate power, as psychologists usually do.

Pioneer psychological experiments suggest that power changes individuals in various ways including their cognition, affect, and behavior; the power primes employed in many of these experiments are, however, usually hypothetical (i.e., individuals are primed to imagine having or having had power), and are prone to inducing demand effects (Sturm \& Antonakis, 2014). Additionally imagining having power or recalling experiencing it is not necessarily the same as having real power at the moment of decision making (Flynn, et al., 2011). Furthermore, outcome measures are either hypothetical or the stakes involved are low. Still, that individuals demonstrate corruptive behavior in imaginary or low stakes situations suggests that power does indeed have strong effects, though increasing the stakes and giving real power would make for more ecologically valid and realistic findings (Sturm \& Antonakis, 2014).

Building on previous research, we designed two experiments in which we gave exogenously appointed leaders real power over their follower(s) and gave leaders monetary incentives to take advantage of their power for their personal gain. We also allowed for the emergence of participant-endorsed social norms, indicating what decisions responsible leaders should take with respect to payoff distributions for themselves and their followers; thus, we could observe the extent to which leaders behaved in an antisocial manner and were willing to violate social norms as a function of power.

Our contributions are threefold: First, we examine to what degree the situation (i.e., power) has an impact on leader corruption. We observe these results in one-shot settings as well as in repeated decision settings having real social norms of which leaders were made aware. These results extend what we know because previous research had not examined what individuals 
do when informed of a social norm to which they themselves subscribed and whether they will go on to violate it when having received power. Second, we study the effect of stable individual differences (e.g., personality and testosterone) on leader corruption, in conjunction with a situational manipulation; previous research on power has largely ignored interactionist explanations as well as the effects of physiological variables. Third, we use an incentivized leadership decision task, give real power to leaders, and allow the leaders to have a consequential impact on followers having real stakes over time. Thus, our findings have important implications for practice both in terms of leader selection but also regarding leader governance systems.

\section{What is leader corruption?}

For the purpose of our study, we must first be very clear about what we mean by corruption, because the definition will drive how we measured it and the conditions under which we observe participants to whom we give power. According to lay definitions, corruption is usually viewed as individual moral deterioration that results in an abuse of power for personal gain that contravenes social or moral norms (cf. The Oxford English Dictionary Online, 2000).

Academic definitions are similar. As concerns individuals who exercise authority on behalf of others, definitions usually include an "element of private gain (usually financial, although power, prestige and perquisites could be included) for individuals who exercise that authority" (Sherman, 1980, p. 479). Additionally, Ashforth and Anand (2003, p. 2) define corruption as "misuse of authority for personal ... gain" and that "misuse refers to departures from accepted social norms" (Anand, et al., 2005, p. 10). Important to note too is that implicit expectations of how leaders should be in terms of their prototypical (or antiprototypical) characteristics are rather stable across contexts and generalizable (Epitropaki \& Martin, 2004). We expect that individuals should largely agree on how leaders should behave when they are given power. Thus, we can obtain a relatively good measure of corruption that gauges the extent 
to which (a) leaders use their power for their personal gain, and/or (b) leaders contravene social norms, as a function of power, to benefit themselves to the detriment of the common good.

As for the causes of corruption, research suggests that social situations as well as personal factors may induce corruption. We explain these two pathways in greater detail next.

\section{The situation component of corruption: Power}

Power is usually thought of as the means by which leaders influence followers (Etzioni, 1964; French \& Raven, 1968). Power, as applied in interpersonal settings is about imposing one's will (Finkelstein, 1992). Specifically, it can be defined as "having the discretion and the means to asymmetrically enforce one's will over others" (Sturm \& Antonakis, 2014). There are two important components to this definition that are relevant to our study: (a) discretion, which refers to choices available to the leader to enforce his or her will, and (b) enforcing his or her will over others, which refers to those who are dependent on the leader. Thus, the more options and subordinates one has the more one has power.

Psychological studies have shed some interesting light onto the probable powercorruption link. As concerns the effect of power on individuals, overall, it appears that those who have power rationalize and legitimize its discretionary use to maintain social status differentials (Goodwin, Operario, \& Fiske, 1998; Kipnis, 1972; Magee \& Galinsky, 2008); in essence power appears to makes individuals self-serving (Kipnis, 1972). There are several mechanisms that give us reason to believe that power may corrupt. Power appears to engender a sense of entitlement, emotional disengagement, and self-interest (Kipnis, 1972). In other words the powerful see the less powerful as less worthy and evidence also suggests that the powerful may even become more prejudiced (Guinote, Willis, \& Martellotta, 2010); they also tend to stereotype the less powerful (Fiske, 1993; Goodwin, Gubin, Fiske, \& Yzerbyt, 2000). In addition, the powerful tend to become very self-centered. Experimental studies show that powerful individuals tend to ignore 
the advice of others and demonstrate reduced perspective taking (Galinsky, Magee, Inesi, \& Gruenfeld, 2006; Tost, Gino, \& Larrick, 2012); those with power may not be able to see how the individuals who depend on them are affected by their decisions (particularly by antisocial decisions). It also appears that power makes individuals overconfident (Fast, Sivanathan, Mayer, \& Galinsky, 2012) and [men] more likely to sexually harass (Bargh, Raymond, Pryer, \& Strack, 1995); such findings suggest that those who are powerful may be prone to engaging in more selfserving behavior and somehow feel immune to sanctions. Findings also suggest that those who have or are given higher status (which is a consequence of receiving power too) behave more unethically (Piff, Stancato, Cote, Mendoza-Denton, \& Keltner, 2012); the powerful are also immune to others' suffering and exhibit less compassion (van Kleef et al., 2008).

Overall, these psychological channels imply that those who have power may be blinded to social norms, behave in socially inappropriate ways, feel superior to others, and fail to see wrong from right; additionally, those with power will disregard others and see them as means to satisfying ends (Keltner, Gruenfeld, \& Anderson, 2003). Thus, with respect to individuals having received a low amount of power, we expected individuals having received a high amount of power to disregard social norms and to serve their own interests even if their opportunistic behavior hurts others and reduces social surplus (i.e., the powerful will behave in a corrupt manner).

H1: Leaders having received high power will be more corrupt than will those leaders who have received low power.

To better understand the aforementioned mechanism through which corruption occurs we provide a more formal and descriptive account of the effect of power on corruption. Our more detailed explanation will help illuminate the tradeoff between how leaders can maximize their gains versus what is best for the welfare of their group of followers; it will also make clear on 
what basis we chose the parameters of the incentivized games and why in one of the experiments we engendered strong social norms.

For expositional simplicity assume that a leader $i$ who has an initial endowment $L$ can make a choice $x \in\left[0, x^{\max }\right]$. For illustrative purposes it is best to think of $x$ as a simple allocation decision. Increasing $x$ has two effects: (a) it increases the payoff of the leader $i$, and (b) it decreases the sum of payoffs of a group of $n$ followers who have a joint endowment $F$. We denote the positive effect of increasing $x$ by one unit on the leader's payoff by $l$ and the negative impact on the sum of the followers' payoffs by $f$. Social surplus $S(x)$ is therefore given as:

$$
S(x)=L+l x+F-f x
$$

To make the problem interesting from an efficiency point of view, we assume that increasing $x$ is socially inefficient; that is, $f>l$, so that $S(x)$ is decreasing in $x$. In other words, as the leader increases his or her payoff, the sum of followers' payoffs is decreased by a greater amount $^{1}$. Thus, the more the leader benefits the greater is the extent to which the leader destroys public wealth. From the leader's perspective, we can model what utility (i.e., benefit) the leader obtains by taking a particular decision. We make the assumption that that the leader's utility function contains two elements. On one hand, the leader benefits from increasing his or her own monetary payoff $(L+l x)$; this aspect of utility is purely economic. On the other hand-and supposing a normal functioning leader who does not have any psychological impairments or is under cognitive load — the leader incurs some degree of psychological cost if his or her behavior violates social norms (see Kessler \& Leider, 2012; Krupka \& Weber, 2013; Mazar \& Ariely, 2006; Mead, Baumeister, Gino, Schweitzer, \& Ariely, 2009). In this context a social norm corresponds to a maximum level of $x$ (the leader's choice) that society, or at least a relevant

\footnotetext{
${ }^{1}$ Note that in setting the parameters for the incentivized (dictator) games we set the ratio of leader gains to follower losses to be 5 to 6 ; every gain of 5 units in leader payoffs meant a loss of 6 units in follower payoffs.
} 
subgroup of society (e.g., members of an organization, the leader's followers, etc.), accepts as justified for a leader having power $p$ (i.e., number of individuals the leader can affect and the discretion the leader has.). We denote such a social norm as $n .^{2}$ The leader's utility, where $\alpha$ measures the disutility of a one-unit deviation from the social norm, can therefore be written as:

$$
U_{l}(x)=L+l x-\alpha(p) \max [x-n, 0],
$$

Theoretically, powerful leaders suffer less from deviating from social norms than do less powerful leaders (i.e., $\partial \alpha(p) / \partial p<0)$. This assumption is well-founded given that, as we discussed previously, studies show that powerful individuals are shielded from social norms and from seeing how their decisions may impact those below them. Thus, power will act as a "buffer" to leaders and make antisocial decisions less psychologically taxing on them.

Leader $i$ thus has an incentive to increase $x$ as long as the marginal utility (the increment in benefit obtained) from doing so is positive. Obviously, this is always the case as long as the leader does not violate the social norm $(x \leq n)$. In this region the leader can simply improve his or her personal payoff without suffering from knowledge of violating social expectations. If $x$ is beyond the level deemed acceptable by the social norm $(x>n)$, increasing $x$ is optimal only if the utility loss from norm violations $(\alpha)$ is smaller than the utility gain caused by a higher payoff $(l)$. Put alternatively, the leader will be willing to incur the psychological cost of violating social norms if he or she gains what will be a sufficiently high payoff (refer to the Figure 1).

[Figure 1 here]

\section{The person component of corruption: Effect of Individual differences}

Although power may corrupt, there are also individuals who might be predisposed to become corrupt. Recently, there has been increased interest in understanding the characteristics

\footnotetext{
${ }^{2}$ The social norm is likely to be a function of $l$ and $f$, and potentially also of the player's endowments $L$ and $F$. Because we hold these variables constant in the experiment, we abstract from this point to keep the notation as simple as possible.
} 
of "good" (virtuous) leadership, and various streams of research have emerged including leader moral development (Loviscky, Trevino, \& Jacobs, 2007; Turner, Barling, Epitropaki, Butcher, \& Milner, 2002), leader integrity (Palanski \& Yammarino, 2009; Simons, Palanski, \& Trevino, 2013), and other bright (or dark) side variables, including hubris and narcissism (Judge, LePine, \& Rich, 2006; Judge, Piccolo, \& Kosalka, 2009).

We focused on two key individual difference variables, honesty and testosterone, which may predict corruption, particularly in "weak" situations (Kenrick \& Funder, 1988; Mischel, 1977); these situations are characterized by few constraints on individual behavior, and where individuals have the freedom to self-express, as do powerful individuals. That is, the more discretion an individual has the more likely individual differences will matter in predicting consequential outcomes (e.g., see Barrick \& Mount, 1993).

Trevino (1986) argued that individuals who are more morally developed will resist making unethical decisions. There are various ways to measure moral or ethical inclination. We opted to use a personality measure, honesty, as conceptualized in the "big six" HEXACO personality model (Lee \& Ashton, 2004, 2008). Low levels of honesty have been linked to counterproductive behaviors as well as psychopathy, narcissism and Machiavellianism (Lee \& Ashton, 2005; Lee, Ashton, \& de Vries, 2005; Lee, Ashton, Morrison, Cordery, \& Dunlop, 2008). In related lines of research DeCelles, DeRue, Margolis and Ceranic (2012) found that individuals having a low moral identity were more prone to exhibit self-interested behavior when given power; Chen, Lee-Chai, and Bargh (2001) found similar results with respect to individuals who were high on exchange (as opposed to communal) orientation (see also Pearce, Manz, \& Sims Jr, 2008; Trevino, 1986). Thus, we would expect low honesty to accentuate the effect of power on outcomes; that is those who are honest should be shielded from the corruptive effects of power and those who are dishonest will abuse their power for personal gain. 
H2: The effect of power on corruption will be moderated by honesty such that power will more strongly predict corruption at low levels of leader honesty.

Note, the above hypothesis is an interaction hypothesis about how honesty predicts corruption when an individual has high power (cf. DeCelles, et al., 2012; Trevino, 1986). In the presence of an interaction, the main effect captures the impact of honesty on corruption for those who have low power only. Recall, we define corruption as individual moral deterioration that results in an abuse of power for personal gain that contravenes social or moral norms. Thus, we did not expect low-power individuals to be corrupted. Thus, we expected a nil effect for honesty for the low power condition (i.e., a nonsignificant simple effect).

We also looked at a key hormone, testosterone. Testosterone might be a potential explanatory variable of corruption, particularly because it has been linked correlationally as well as causally (via exogenous manipulation) to antisocial and egocentric behavior (Bos, Terburg, \& van Honk, 2010; Dabbs \& Dabbs, 2000; Wright et al., in press; Zak et al., 2009). Testosterone also predicts social dominance (Rowe, Maughan, Worthman, Costello, \& Angold, 2004) and various deviant behaviors (Mazur \& Booth, 2014); it also appears to make individuals less responsive to stress (Handa, Burgess, Kerr, \& O'Keefe, 1994) as well as more sensitive to rewards and less sensitive to potential punishments (van Honk et al., 2004). Interestingly, testosterone predicts reduced levels of empathic accuracy (Ronay \& Carney, 2013; van Honk et al., 2011); the latter results are of note because they suggest that testosterone may act in a similar way that power does by buffering individuals from the psychological costs incurred when making antisocial decisions.

Simply put high testosterone individuals are worse at detecting thoughts and feelings of other individuals in social interactions; coupled with increased interest in rewards and reduced sensitivity to potential punishments (i.e., in the case of our experiment decreased psychological 
costs due to making antisocial decisions) suggests that high testosterone individuals will be "tuned-off" from feeling the emotional impact their decisions will have on others and will focus on maximizing their payoffs. Also, given the heightened sensitivity of high-testosterone individuals to material rewards, we expect the above to occur in situations where rewards are very salient (i.e., high power condition with more discretion). In other words, we expect testosterone to moderate the effect of power on corruption such that the effect of power on corruption will be amplified by individuals having high levels of testosterone. Additionally, as explained above, we expected a nil effect of testosterone for the low-power group, particularly given the lower salience of rewards in the low power situations.

H3: The effect of power on corruption will be moderated by testosterone such that power will more strongly predict corruption at high levels of leader testosterone.

\section{Overview of the experiments}

For both experiments, we used variants of the dictator game (e.g., Kahneman, Knetsch, \& Thaler, 1986); in this game a dictator-who is not called that for the purpose of the experimentis given full autonomy to decide how a "pot of money" is to be apportioned between himself or herself and followers. Followers are passive have no say in the decision; thus, the leader is afforded full discretion in the decision-making process. We used no deception, and fully informed leaders of the microeconomic structure we set up, as well as the decisions and payouts available to them; in this way, we could "ensure a direct and salient connection between decisions taken and desired monetary outcome, and therefore $[\ldots]$ the interpretability and the internal validity of the experiment" (Zizzo, 2010, p. 77).

Our first experiment makes use of a simple between-subject design in which we exogenously vary two dimensions of power independently from each other: The number of followers ( 1 or 3 followers) and leader discretion, that is, the number of options available to the 
leader (3 or 4 options). Each appointed leader sees only one condition-without knowing about the existence of the other conditions - and makes a decision in a one-shot experiment. This experiment allows us to identify whether leaders who find themselves in a powerful decision environment are more likely to make self-regarding, but socially inefficient decisions than do low power leaders. Additionally, we do not expose leaders to social norms nor are we concerned of the effects of selfishness (which is also a component of corruption); thus, leader decisions in this experiment reflect the upper bound effect of leader corruption.

Our second experiment is more ambitious and models the effect of power in a more realistic way. Here we manipulated power (number of followers and options) both between and within-participants and exposed participants to social norms that they helped shape before they received power. Our design allows us to identify the corrupting process of power over time. We observe how subjects react to an increase in power, with knowledge that they are expected to make socially responsible decisions. We also model various individual differences so as to determine to what extent they predict corruption in conjunction with power. Given that there is an element of selfishness in corruption too, in this experiment we isolate the effect of power on corruption from the effect of selfishness. This study sheds unique light on whether individuals with power and with a certain disposition become irresponsive to social norms over time.

Prior to reporting on our experiments, we provide evidence for the validity of our manipulations next.

\section{External check on manipulating power}

Given our designs, we did not wish to make the manipulations salient to participants either before or after the dictator games because it would engender demand effects for any pre- or post-experimental measures, including manipulation checks. Thus, instead of asking leaders of the games whether they felt powerful, we opted for an objective (and external) manipulation 
check by using an independent sample of participants similar in background to the participants in the experiments $(n=90)$ but who did not partake in the games. In a between-subjects design, we asked these participants to rate the extent to which a leader would have power and feel powerful in one of the three power conditions. Specifically, we provided information regarding the options available to the leader, and the payouts to the leader and the follower. We presented the participants to one condition only (i.e., either baseline/low power, medium power, or high power). These conditions were described as follows:

1. Baseline/low power: Leader has 1 follower and 3 options to split money as follows, to the leader and follower: Option 1: 10 to 7; Option 2: 9 to 9; or Option three: 15 to 1. The option that maximizes social welfare is the second option and the anti-social option is the last one (note, invoking the anti-social option as compared to the first/default option gives the leader a gain of $15-10=5$ to follower losses of $1-7=-6$ ).

2. Medium power: Leader has 3 followers and 3 options to split money as follows, to the leader-each follower: Option 1: 10 to 7; Option 2: 9 to 9; or Option 3: 15 to 5 (note: invoking the anti-social options maintains leader gains, $15-10=5$ to follower losses, $(5-7) * 3=-6$, that is $5 / 6$, in this set-up too).

3. High power: Leader has 3 followers and 4 options to split money as follows, to the leader-each follower: Option 1: 10 to 7; Option 2: 9 to 9; Option 3: 15 to 5; or Option 4: 25 to 1 (again: leader gains to follower losses remain constant in this set-up; for the very antisocial option they are $25-10=15$ gain for the leader and $(1-7) * 3=-18$ for the followers. Hence the ratio is $15 / 18=5 / 6)$.

For each of the conditions, which we depicted using neutral terminology, we asked the participants to respond to three questions with respect to Person A (the leader) and Person B (or 
Persons B, C, and D in the case of 3 followers). These three questions were rated using a scale of 1 (completely disagree) to 7 (completely agree):

1. Person A will feel that he/she will have a lot of power given the choices he/she has to distribute the money.

2. There is a large asymmetry between the choices available to Person A and B (or Persons $\mathrm{B}, \mathrm{C}$, and D).

3. Given this situation, Person A really has a lot of power.

Important to note is that Question 2 is a control question: that is, we did not expect it to be significantly affected by the between subjects manipulation, given that there was complete asymmetry between the choices for all leaders — whether in the baseline, medium, or high-power condition — and the follower/s who had no choice.

For data analyses, we first created an index of power, which was the mean of questions 1 and $3($ Cronbach alpha reliability coefficient $=.70 ;$ Spearman-Brown correction for 4 items $=.82$, indicating that the index is highly reliable). Using Stata (ver. 13), we then estimated a seemingly unrelated OLS regression of the form:

$$
\begin{array}{ll}
\operatorname{power}_{(q 1, q 3)}=\beta_{0}+\beta_{1} \text { medium }+\beta_{2} \text { high }+e & \text { Eq. } 3 \\
\operatorname{power}_{(q 2)}=\gamma_{0}+\gamma_{1} \text { medium }+\gamma_{2} \text { high }+u & \text { Eq. } 4
\end{array}
$$

Where, $\operatorname{power}_{(\mathrm{q} 1, \mathrm{q} 3)}$ is the power index, and $\operatorname{power}_{(\mathrm{q} 2)}$ is the power control question, the intercepts $\beta_{0}$ and $\gamma_{0}$ are the coefficients of the omitted categories (i.e., the baseline conditions), medium is the medium power condition, and high is the high power condition, and where $\operatorname{cov}(e, u)$ is estimated. We report the results of the manipulation check in Table 1.

[Table 1 here]

As is evident in Table 1, for the power index equation (Eq. 1), the medium power condition was 
significantly higher than the baseline (i.e., low) condition $(p<.05)$. In addition, a Wald test indicated that the high power condition was significantly higher than the medium power condition $(p<.05)$. A joint Wald test combining the two above tests was highly significant $(p<$ .001). Furthermore, results for the control question were not significant. The findings point to the fact that the power manipulation we designed would have its intended effects.

\section{Study 1}

\section{Sample and Design}

We recruited 478 participants from three classes in the business school of a Swiss state university to participate in the experiment. We made participants aware their earnings would be dependent on their own decisions or decisions of other persons who were in the same room. Thus participant leaders knew that making a socially inefficient decision would economically harm an individual or several individuals present in the room.

From the pool of participants, we randomly appointed 162 as leaders (mean age $=21.36$, $\mathrm{SD}=2.04 ; n=100$ males); the rest of the participants were assigned the role of followers. Leaders were randomly attributed to one of four conditions in a two by two design. Leaders were given either 3 followers (high power) or 1 follower (low power). Additionally, leaders were given either four decision (high power) or three decision options (low power). Refer to Table 2 for the parameters of the game. As is evident from the table, the parameters of the game were such that relative to the default decision, a prosocial decision increased public wealth, but antisocial decisions destroyed it.

\section{[Table 2 here]}

Followers were anonymously and randomly assigned to leaders. Leaders received an instruction sheet informing them of the decision-making options to their disposal (as function of the condition they were in) and they had to make a single decision. We informed them that their 
decision would affect the payoffs of their follower/s, who were in the same room; of course, given that all participants played anonymously, leaders did not know who were their assigned followers and leaders, of course, had full discretion and decision making power.

The decision options were given to leaders such that the Option 1 was presented as the "default" option (and labeled as such). Although not a social norm, presenting this option as the "default" engenders a norm of sorts that can be thought of as an anchor point (Tversky \& Kahneman, 1974); thus, to the extent that individuals decide something different from this anchor point by invoking the antisocial decision as a function of power will attest to the strength of the power manipulation. In other words, choosing the default options "goes against" our theory that power corrupts; if we find that participants with high power do not chose the default option but an antisocial option, then we can claim indeed, power corrupts.

All other decision options were presented in terms of change from the default option, and referred to as "option 2," "option 3," and if relevant, "option 4." The options were describe in terms of their payouts to the leader and the follower/s. In the "default" allocation, the leader was paid slightly more than the follower. In the "prosocial" allocation, leader-follower payoffs were evened-out at a cost to the leader. In the "anti-social" allocation, leaders received substantially higher payouts but also destroyed public surplus (i.e., reduced the total payouts to the group). Finally, if leaders had the "very anti-social" option available, they could greatly profit from their position of power (note, we did not use the terms "prosocial" or "antisocial" in the instructions to the participants).

As an example of the level of detail we gave leaders, a low power leader having 1 follower and 3 options was informed that the default remuneration they would receive would be 220 points for the leader and 190 points for the follower; hence the default option was noted as: “Option 1: Leader +0 points; Follower +0 points." The prosocial option was presented as "Option 
2: Leader -10 points; Follower +20 points" and the antisocial option was presented as "Option 3 : Leader +50 points; Follower -60 points." Leaders having one follower and four options had the very antisocial option described as “Option 4: Leader +150 points; Follower -180 points". Note, in the description of the options, we explicitly mentioned "change nothing" (default), or “increase," or “decrease” the leader's or follower's remuneration (depending on decision taken). As with the external manipulation check study, relative to the default option, leader gains to follower loses are kept constant at 5/6, across all conditions.

After leaders made their decision, payoffs for each participant were calculated and they were each paid accordingly. In order to maintain anonymity, participants' payments were linked to a personal identification code which they knew alone.

\section{Results}

We gave all participants a show-up fee of Sfr .50 (i.e., $\$ 0.56^{3}$ ) to which we added the payoffs from the leader decision. Leader payoffs ranged between $\$ 12.30$ to $\$ 21.24$ (mean $=$ $\$ 15.60, S D=\$ 3.26$ ), which are relatively large considering the amount of time it took to brief participants and run the experiment (about 15 minutes). Refer to Figure 2 for distribution of leader decisions across conditions. Telling patterns of results are evident from visual inspection: Giving leaders more followers or more options increase the likelihood of leaders taking an antisocial or very antisocial decision.

In order to statistically analyze the four conditions simultaneous, and given the default option communicated to leaders, we operationalized corruption as invoking a socially inefficient decision; that is one that would profit the leader greatly to the determinant of the public good. Thus, antisocial or very antisocial decisions were coded as " 1 " and prosocial or default decisions

\footnotetext{
${ }^{3}$ Conversion rates for points were presented to participants in terms of Swiss Francs. Henceforth, we report all amounts in US\$ at relevant market conversion rates for when the experiments were run.
} 
at " 0 ". Results of a probit model indicated a significant main effect for having more options and followers.

[Figure 2, Table 3 here]

Having more options or more followers had an equal effect on incidence of corruption, $\chi^{2}(1)=.04, p>.10$. We report estimates from the main-effects model (note, adding the options*followers interaction was marginally significant, $\beta=.71, S E=.43, z=1.66, p<.10)$. To better understand the magnitude of the effect, leaders having fewer options and fewer followers had a predicted probability of .39 of invoking an antisocial decision. However, with fewer options and more followers the probability was .61. Similarly moving from having more options and few followers to more options and more followers increased the probability of making a corrupt decision from .59 to .78 . Follow-up tests indicated that the predicted probability of the lowest power condition was significantly lower than the other three conditions both overall $\left(\chi^{2}(3)\right.$ $=22.59, p<.001$ ) and individually (all $p$ 's $<.05$, Bonferroni corrected for multiple testing). Additionally, the two "medium-power" conditions (i.e., having fewer options and more followers, or having more options and fewer followers) were indistinguishable, $\chi^{2}(1)=.04, p>$ .10. The predicted probability in the high power condition was significantly greater than the average probability of the other three conditions combined, $\chi^{2}(1)=18.72, p<.001$; it was also significantly greater than the average probability of the two medium power conditions, $\chi^{2}(1)=$ $19.82, p<.001$. These results largely support H1: Power corrupts.

\section{Brief discussion}

Our results clearly demonstrated that leaders were more likely to take advantage of their asymmetrical decision-making power to serve themselves when having more options or followers. Leaders were most corrupt when having the highest level of power. Even though 
followers of leaders were in the same room as the leaders, and leaders knew that their decision would directly impact their follower/s payoffs, they were still more likely to take sociallyinefficient decisions when having more power. Although we did make mention of a default decision to leaders, these results are upper bound estimates given that we did not induce social norms nor did we partial out the effects of leader selfishness. Of course, corruption in toto does include an element of selfishness and it is important to have a full estimate of the effect; however, to isolate the "pure" treatment effect of power on corruption necessitates that we remove selfishness from corruption, as we did in the following experiment.

\section{Study 2}

\section{Design}

To obtain an observable measure of corruption we again used a variant of the dictator game with real power and consequential monetary stakes. More power meant having more discretion and impact on more individuals. Here, the leader (i.e., the "dictator") had to make decisions over several rounds regarding how to pay his or her followers. In this way, we could test whether power, which we manipulated, or the person, which we premeasured in terms of stable individual differences drive leader corruption over time. Refer to Figure 3 for an overview

of the design; as is evident, we split up data gathering and used different methods, which should reduce common source and common method effects (Podsakoff, MacKenzie, Lee, \& Podsakoff, 2003; Podsakoff, MacKenzie, \& Podsakoff, 2012); our estimates, particularly that of the treatment effect can thus be causally interpreted given that, in any case we randomly assigned power to leaders (Antonakis, et al., 2010).

[Figure 3 here]

As we show in the figure, data gathering was broken up into three major time periods: “pretests," "pre-experimental," and “experimental." We observed corruption in the experimental 
period, wherein leaders partook in the dictator game. We gathered several pre-experimental measures right before the dictator game and several weeks before the experiment, we also gathered data on various individual-difference measures.

The dictator game was played over three stages having five decision rounds each, which gave the experiment a time dimension regarding payoffs. Initially, all leaders were in charge of one passive follower and could choose among three basic payoff allocation, as per the previous experiment (but using different point allocations and conversion rates): (a) a "default" allocation; (b) a "prosocial" allocation; or (c) an "anti-social" allocation. Our experimental manipulation consisted in giving more power to a randomly selected subsample of leaders twice. In the power condition we gave leaders two more followers in Stage 2; we then added a very antisocial decision option in Stage 3, which if invoked greatly profited the leader to the detriment of the public good. As in the previous study, to avoid introducing confounds in our manipulations we kept the ratio of leader gains to follower losses constant across the power manipulations (at 5/6).

\section{Sample}

Our useable sample was 240 students, from a business school of a Swiss state university, who participated anonymously in the experiment; we used randomly generated identifier codes to link participants' data ${ }^{4}$. From this sample, we appointed $168^{5}$ as leaders $(61.31 \%$ males, mean age $=21.10, S D=1.61)$. To maximize our leader sample size participants played in the dictator game twice and those who we appointed as leaders were only leaders in one of the two games ${ }^{6}$.

\footnotetext{
${ }^{4}$ The initial sample was 270 . However, some participants did not complete all measures or misplaced their identifier codes and could not be matched to their leader-follower group (12 of these participants were leaders).

${ }^{5}$ We originally had 170 appointed leaders. To ensure a degree of subject homogeneity, we excluded two clear outliers: One male participant who had an abnormally high level of testosterone $(406.15 \mathrm{pg} / \mathrm{mL})$ and one female participant who was 44 years old. Excluding these subjects did not substantively alter results.

${ }^{6}$ Because the leaders in the first game did not know that there would be a new game, there was no possibility that they behaved in a way that could be explained by hidden reciprocity. We informed participants after the first game that there would be one more game only. More importantly, participants had no feedback on any of the decisions taken in the prisoner's dilemma or the first dictator game. Only after the second dictator game was finished, did we
} 


\section{Procedure and manipulations}

Pre-experimental measures (i.e., the individual difference pretests) were gathered from participants in scheduled classroom sessions using paper and pencil tests. The experiment was conducted in the behavioral laboratory of the university. Subjects reported to the laboratory in scheduled sessions where we gathered pre-experimental and experimental data (note to prevent contamination between subject groups during the experiment, we kept subjects apart in different locations). Similar to Study 1, we informed participants that their payoffs would depend on how they or others in the schedule sessions took certain decisions. We gathered all experimental data using z-Tree (Fischbacher, 2007).

After being briefed in the lab, participants first played a prisoner's dilemma, which we used to premeasure their behavioral selfishness. Next, prior to appointing leaders we asked all participants which payoff options a "responsible leader" should chose (we report here data from the full sample $n=270$ because this is the information that was provided to the leaders). This poll — whose results we communicated to participants before the dictator game in each sessionindicated that, overall, $80.74 \%$ of the participants endorsed the default option (which was also labelled as such to leaders when they played the game) and $15.93 \%$ the prosocial option. Only $3.33 \%$ of participants chose the antisocial decision option. Thus, if leaders chose an antisocial decision as a function of power demonstrates the robustness of the power manipulation. Because all subjects, both in the high and low power conditions, were communicated this information, the socially-induced demand on leaders was to behave responsibly by increasing public welfare.

debrief participants and inform them of all decisions and payoffs. Thus, we can be confident that there would be no retaliation effects by Game 2 leaders. In any case, because playing the game a second time was unexpected and may have affected findings (via surprise or other mechanisms), we controlled for this order-effect as a covariate (i.e., "Game 2 Leader"); as we report later in the Results section, its effect went in the opposite direction of a retaliation effect (i.e., Game 2 leaders were less corrupt, although marginally so). 
For the dictator game we randomized leaders to a high or low power condition, where leaders had full discretion on payouts, which they made over three stages (five decision rounds each). In Stage 1, all leaders were each initially in charge of a passive follower and decided among three payoff allocations (100 points $=\$ 2$, see Table 4 "Baseline Payoff”): (a) "default," leader payoffs (100) were higher than the follower's (70); (b) "prosocial," where payoffs were evened-out (90: 90) at a cost to the leader while increasing social surplus (+10); and (c) "antisocial," where leader gains increased $(+50)$ at the cost of social surplus $(-10)$ and the follower's payoff (-60). Again, the ratio of leader gains to follower losses is always 5/6 (i.e., in the above case, 50/60). As with the previous experiment, we did not label any of the options with the terms "prosocial," or "antisocial," but only used the term "options" along with descriptions of the payoff consequences.

\section{[Table 4 here]}

We randomly gave some leaders $(n=72)$ more power twice: (a) in Stage 2 (see Table 4 "Medium Power Payoff”), we assigned these leaders two additional followers so that they controlled more followers and resources but left unchanged the monetary implications of the antisocial choice for the leaders while keeping the ratio of leader gains $(+50)$ to total follower losses $(-3 *(70-50))$ constant at 50/60; (b) in Stage 3 (see Table 4 “High Power Payoff”), we introduced a fourth "very antisocial" option, greatly increasing the leader's payoff $(+150)$ and reducing follower payoffs $(-3 *(70-10))$, while maintaining the aforementioned ratio $(150 / 180=$ $50 / 60)$.

As it is clear from the parameters of the dictator game, the prosocial exercise of power would increase public welfare (i.e., total group payouts increase) and the antisocial choice would decrease public welfare (i.e., total group payouts decrease). 


\section{Measures}

Dependent variable - corruption: In the previous study, we only measured the aspect of corruption having to do with person gain; in this experiment, we included the second aspect of corruption: Contravention of a social norm. As mentioned, to have a valid measure of social norms, we induced an endogenous social norm before participants were assigned the role of a leader or follower. We communicated the result of this poll to all participants, and thus both to future high and low power leaders, before the dictator game. Given that we gave leaders a monetary incentive to invoke the antisocial decision, which would destroy social surplus in this experiment we operationalized corruption as an increase in norm-violations over time. We introduced a time dimension too because it is possible that the corruptive effect of power might not be immediately evident; that is, an individual may become gradually more corrupt with time (cf. Bluedorn \& Jaussi, 2008; Shamir, 2011) —a kind of "slippery slope” effect. Note, by communicating the social norms to future leaders, we create demand effects on the subjects to act "responsibly." All future leaders, both in the high or low power conditions were exposed to this demand effect; thus, to the extent that we are able to observe individuals that contravene the social norm as a function of high power makes for a very robust test of the power manipulation. Also, the social norm is ecologically valid because it was based on the very participants who would partake in the dictator game before they knew if they would play as a leader or a follower.

Independent variables: We erred on the side of caution in including more rather than fewer measurable individual differences that might predict corruption; by controlling for preexisting differences in some variables that may predict corruption, we also increase statistical power in the model (Keppel \& Wickens, 2004; Maxwell, Cole, Arvey, \& Salas, 1991). For individual differences to be valid predictors of outcomes they should be stable over time and, ideally, heritable (Antonakis, et al., 2010); individual differences having such properties would 
unlikely vary as a function of corruption per se or because of unobserved factors that predict corruption. Individual differences with such characteristics would therefore be exogenous. Personality, intelligence, as well as hormones largely exhibit cross situational and temporal stability (Bouchard \& Loehlin, 2001; Bouchard \& McGue, 2003; Ring et al., 2005). These, as well as a person's sex, have been exogenously "manipulated" by nature, which allows for relatively strong causal inference in a predictive model (Antonakis, et al., 2010).

In terms of hormones, we measured baseline testosterone using saliva Luminescence Immunoassay (IBL International, 2008); we also measured cortisol as a control variable. How testosterone predicts outcomes is similar whether using baseline testosterone or whether exogenously manipulating it (Bos, et al., 2010; Dabbs \& Dabbs, 2000; Zak, et al., 2009). Also, exogenous administration in men (who have much higher levels of testosterone than women) is difficult to accomplish (cf. Bos, et al., 2010), in addition to posing important ethical concerns. Additionally, baseline (endogenous) testosterone, is both highly stable over time (Liening, Stanton, Saini, \& Schultheiss, 2010; Sellers, Mehl, \& Josephs, 2007) as well as heritable (Harris, Vernon, \& Boomsma, 1998) and thus can be considered as exogenous in our specifications.

Before the experiment, we obtained three saliva samples, which we pooled to increase the reliability of the hormonal measures. Participants drooled salvia via a straw into three polypropylene SaliCap® tubes (IBL International, 2008). We obtained the three saliva samples in the morning for all participants between 08h45-09h30; moreover, participants had been under observation since $08 \mathrm{~h} 00$. Because testosterone levels can change as a function of situational factors all participants were measured at the same time and in the same conditions; thus, the testosterone levels of participants could not be altered by unobserved factors correlated with corruption. Also, to ensure the stability of the testosterone measure, on the day of the dictator game we collected three more samples between 09h00-12h00 (depending on the time the 
participants partook in the experiment, which was not the same for all participants). The observed correlation between Time 1 and Time 2 testosterone for all participants was very high, $r(168)=$ $.85, p<.001$; this coefficient was precisely the same when controlling for time differences in the Time 2 measure. This result attests to the stability of relative individual-differences in testosterone over time, irrespective of the treatment, as others have found too (Sapienza, Zingales, \& Maestripieri, 2010).

Important to note is that when using testosterone as a predictor, it is best to model the raw score while controlling for sex given that men have testosterone levels that are many times higher than those of women (cf. Ronay \& Carney, 2013; Sapienza, Zingales, \& Maestripieri, 2009); in our data, males had testosterone levels that were more than five times higher than those of females on the average (see Figure 4). Some researchers standardize testosterone within sex (i.e., separately within females and males) and then pool the standardized data, which are then used as predictors. This procedure equates a high (or a low) testosterone woman to a high (or a low) testosterone man, which obviously confounds the effects of testosterone and sex in a predictive model, particularly because the distribution of testosterone is very different in males and females. Using within-sex standardized measure would thus not answer whether testosterone per se has an effect on outcomes but whether individual-level relative testosterone position within sex has an equal effect on outcomes across sex.

\section{[Figure 4 here]}

As concerns the key personality variable, honesty, we used the HEXACO personality inventory (Lee \& Ashton, 2004), normed, within sex, on Swiss French sample. The HEXACO instrument has demonstrated strong psychometric properties (Lee \& Ashton, 2004, 2008; Lee, et al., 2008).

Control variables: Because our sample was sufficiently large for having one between subjects manipulation, we included several control variables to reduce experimental error and 
ensure maximum statistical power. We provide some justification for the inclusion of the control variables, though we do not draw formal hypotheses for these due to insufficient theory:

1. intelligence, measured with the Wonderlic Personnel Test, which is a well validated test (Wonderlic, 2002); we measured it because country-level intelligence is associated with reduced levels of country-level corruption (Potrafke, 2012).

2. the big five personality factors (i.e., emotional stability, extraversion, openness, agreeableness, and conscientiousness) measured with the HEXACO. We controlled for the rest of the personality factors because personality variables are often correlated with each other; thus it is important to estimate the incremental effect of the target factor beyond the multivariate effects of the rest of the variables (Antonakis, Day, \& Schyns, 2012; Judge, Bono, Ilies, \& Gerhardt, 2002; Zaccaro, 2012).

3. behavioral selfishness; as mentioned previously, we used this measure to ensure that we remove unobserved variance in initial levels of antisocial decisions that may be due to selfishness per se (which thus allows us to capture the pure effect of corruption resulting from power, see Figure 5 for further details); this measure is perfectly observed.

4. three key demographic variables, which may correlate with intelligence and personality, including (a) biological sex, (b) chronological age, (c) whether participants had French as the first language or not (all measures and instructions were given in French); $76.8 \%$ of the sample had French as a first language).

[Figure 5 here]

\section{Results}

\section{Violation of social norms}

Because of our definition of corruption, it is important to show, on a basic level, that more leaders in the treatment having received high power actually violated the social norms, as 
compared to leaders given low power. Thus, here we report on how many of the leaders initially stated that a responsible leader should invoke the prosocial or default option prior to partaking in the dictator game but then went on to invoke an antisocial decision.

Note that the leaders' norms were highly concordant with what all participants said, indicating widely-shared options about what the leader should do. As concerns the leaders (in parentheses, overall sample), $82.14 \%(80.74 \%)$ endorsed the default option, $13.69 \%(15.93 \%)$ the prosocial option, and only $4.17 \%$ (3.33\%) of leaders chose the antisocial decision option. Thus, given these widely shared norms, a check on whether individuals violated what they said—which overlaps highly with what the group said in general — is a reasonably good indication of whether the power treatment made individuals more likely to be corrupt (i.e., violation of their personal norms).

From the total participants in the low power treatment $(n=96)$ who did not initially endorse the antisocial option $(n=94), 79(84.04 \%)$ of them stated that the responsible decision was the default and the rest, 15 (15.96\%), chose the prosocial option. For the participants in high power treatment $(n=72)$ who did not initially endorse the antisocial decision $(n=67), 59$ $(88.06 \%)$ chose the default option and $8(11.94 \%)$ the prosocial option. This difference in distribution of choices between the high and low power leaders was not significant: Likelihoodratio $\chi^{2}(1)=.52, p>.10$.

When the low power participants played the dictator game, and this considering Stages 2 and 3 only (when power was manipulated) 44 (46.81\%) of them remained true to their values and never invoked the antisocial option; also, 75 (79.79\%) invoked an antisocial decision less than half the time. However, only $13(19.40 \%)$ of the high-power leaders remained true to their word, demonstrating a complete disregard of what they previously said; additionally, only 32 (47.76\%) 
of them invoked an antisocial decision less than half the time. These differences in proportions between the two conditions for these results were very significant: $z=3.58$ (for the difference between $46.81 \%$ vs. $19.40 \%$ ) and $z=4.24$ (for the difference between $79.79 \%$ vs. $47.76 \%$ ), $p<$ .01 (Koopman, 1984). These results suggest that those leaders who received power were more likely to violate the social norm of the group as well as the personal norm that they initially adopted (which in most cases was the same as that of the group). In other words, the high-power were more likely to demonstrate a lack of integrity (Palanski \& Yammarino, 2009), which we could directly trace to the power treatment.

\section{Predicting corruption}

Refer to Table 5 for descriptive statistics and variable correlations. As for the payoffs leaders received, they averaged $\$ 59.21$ and ranged from $\$ 35.47$ to $\$ 98.06$, which are rather substantial for experiments of this nature.

[Table 5 here]

We first tested our central hypothesis, that power corrupts (H1), using a multivariate model. We coded antisocial or very antisocial decisions as "1" and default or prosocial decisions as " 0 " and summed them by game stage (i.e., the three stages). We estimated a simple ordered probit model (i.e., a bounded count model given that the dependent variable is not continuous) to predict average incidence of antisocial behavior across leaders as a function of the predictors over time. We used the treatment dummy (i.e., power), two dummy variables identifying the three game stages, the power-stage interaction, and all premeasured individual differences as predictors, and clustered standard errors at the leader level given that the dependent variable is repeated over three stages (note, in Stata, cluster robust standard errors are also robust).

A joint test for the predicted probability of making the maximum amount of corrupt decisions (i.e., 5 per stage) indicated a significant increase in antisocial decisions for high-power 
leaders in Stage 2 (compared to Stage 1) and Stage 3 (compared to Stage 2), $\chi^{2}(2)=28.06, p<$ .001 ; unadjusted univariate results were $\chi^{2}(1)=3.43, p=.06$, and $\chi^{2}(1)=27.96, p<.001$, respectively (note, the predicted probabilities in Stages 1, 2, and 3 respectively were: .20, .25, .39). In terms of predicting the minimum amount of corrupt decision (i.e., 0 per stage), results were similar for the joint test showing a significant decrease: $\chi^{2}(2)=27.08, p<.001$ and the respective unadjusted univariate tests $\chi^{2}(1)=3.43, p=.06$, and $\chi^{2}(1)=25.05, p<.001$ (note, the predicted probabilities in Stages 1, 2, and 3 respectively were: .40, .34, and .22).

Antisocial decisions of low-power leaders were unchanged. The joints tests were not significant, whether when examining marginal effects for maximum $\left(\chi^{2}(2)=.60, p>.10\right.$; the predicted probabilities in Stages 1, 2, and 3 respectively were: .14, .13, and .15) or minimum corruption $\left(\chi^{2}(2)=.61, p>.10\right.$; the predicted probabilities in Stages 1, 2, and 3 respectively were: $.50, .51$, and .49 ); univariate tests were also not significant. These results provide further support for $\mathrm{H} 1$ that power corrupts. For a graphical depiction of the observed increase in antisocial decisions relative to the baseline condition over time, refer to Figure 6.

[Figure 6 here]

Because our conceptualization of corruption has to do with the growth of antisocial decision over time, we estimated a latent growth curve model (Chan, 1998; Duncan, Duncan, \& Strycker, 2006). A latent growth curve model is a powerful statistical technique for studying change (growth) in a dependent variable; in our case the variable of interest is occurrences of antisocial decisions over the three Stages of the experiment. The procedure models initial level of antisocial behavior (i.e., which is called the latent intercept) as well as the growth in antisocial behavior (i.e., the latent slope); the latter variable is the key variable of interest because it captures the rate of change in antisocial behavior. Additionally, using a latent growth curve 
model allows the latent intercept and slope to be dependent variables in the model — in our case we were interested to see whether the power manipulation (as well as the relevant individual differences) predicted initial levels and changes in antisocial decisions. We again modeled incidence of norm-violating decisions as a bounded count and estimated the model using MPlus's (ver 6.12) robust maximum likelihood estimator $(\mathrm{MLR})^{7}$, which can accommodate latent variables models having ordered indicators (Muthén \& Muthén, 2012).

The first latent growth curve we estimated is a stripped-down version. We used the exogenously manipulated variable, power, male and age, as the predictors of the intercept and slope (see Figure 7A for a depiction of the model $)^{8}$. We regressed the slope on the intercept to control for initial differences in antisocial behavior when predicting the slope (i.e., corruption). In this simplified model, only power showed a very strong effect on the slope, coefficient $=1.33, S E$ $=.30, p<.001$ (standardized $\beta=.54)$; however, the effect of power on the intercept was nonsignificant, coefficient $=1.69, S E=1.27, p>.10($ standardized $\beta=.12)$. This result attests to the robustness of the power effect, and gives strong support to the first analysis we conducted using the simple ordered probit model, and confirms the results of the first study for H1.

[Figure 7 here]

We then estimated a latent growth curve that included the covariates and power-covariate interactions (see Figure 7B). To adequately control for sex differences, particularly in testosterone, we estimated two separate latent growth curve models (as reported in Table 6): (a)

\footnotetext{
${ }^{7}$ Standard errors of this estimator are robust to nonnormality of observations. Note, given computational demands of this estimator (which uses numerical integration) we were unable to model errors-in-variables (for intelligence and personality); this issue is irrelevant for the treatment effect given that it is orthogonal to the measures (see correlations of power with measured covariates in Table 5; the absolute average correlation is .04).

${ }^{8}$ Measures of model fit, which test overidentifying constraints, are not available for models with categorical dependent variables estimated with ML estimation. We are not concerned with model fit per se, given that our independent variables are exogenous and the model is, in theory, correctly specified. Though, to give an idea of fit, we reestimated the pooled model with ML declaring the bounded counts as continuous. The chi-square overidentification test was non-significant, $\chi^{2}(4)=5.56, p>.10$ and substantive findings were essentially unchanged.
} 
Model 1, a multiple-group model (Muthén \& Muthén, 2012) using sex as the grouping variable, where we estimated separate models for men and women and where we constrained all crossgroup parameters to be equal (note, because the dependent variables are categorical, this model is actually estimated as a latent class model, with known classes); (b) Model 2, a pooled model including a dummy variable for sex (Sapienza, et al., 2009): For the latter model we also tested whether interacting the dummy variable indicating sex with all the predictors as well as separately with power, testosterone and the power*testosterone interaction improved the model (in this way, we examined whether estimated parameters for men and women were equivalent). The results of the two latent growth curve models produced essentially the same estimates. [Table 6 here]

We report results from the pooled model, which also models sex as a predictor ${ }^{9}$. The results of this latent growth model indicated that behavioral selfishness (standardized $\beta=.26, p<$ .001 ) as well as honesty (standardized $\beta=-.33, p<.001$ ) predicted initial levels of antisocial behavior (i.e., the latent intercept). As concerns the tests of our hypotheses (i.e., predicting the slope, which is our operationalization of corruption), we found a main effect for the power treatment (standardized $\beta=.30, p<.05$ ), supporting H1. That we find this result when including or not the covariates suggests that the power effect is robust. As concerns H2, honesty did not interact with power to predict corruption; we therefore rejected H2. For H3, we found a powertestosterone interaction (standardized $\beta=.44, p<.05$ ), with corruption highest when power and testosterone were both high (Figure 8). Simple slopes analyses (Aiken \& West, 1991) indicated that the slope (i.e., change of the treatment dummy from 0 to 1 ) of power (simple slope coefficient $=1.91, p<.001)$ on corruption was positive and significant when testosterone was

\footnotetext{
${ }^{9}$ To obtain an indication of fit, we again reestimated the pooled model with ML declaring the bounded counts as continuous. The chi-square overidentification test was again non-significant, $\chi^{2}(18)=25.84, p>.10$ and substantive findings were unchanged.
} 
high $(+1 \mathrm{SD}$ from the mean); it was also positive but less so (simple slope coefficient $=.81, p<$ .001) when testosterone was low (-1SD from the mean). These results support H3: The effect of power on corruption was amplified by high testosterone.

[Figure 8 here]

As indicated in Table 6, some of the control variables predicted the slope; these included leaders who were males (standardized $\beta=.36, p<.05$ ) who were younger (standardized $\beta=-.27$, $p<.01$ ), were higher on extraversion (standardized $\beta=.32, p<.01$ ) and on conscientiousness (standardized $\beta=.27, p<.05$ ), and were lower in openness (standardized $\beta=-.38, p<.01$ ). The meaning of these relations is tricky to interpret because they indicate the average effect of these variables on the slope across the high and low power groups. To disentangle this effect one must interact these variables with power. However, given our lack of $a$ priori hypotheses with respect to these variables, and the fact that adding additional interactions increases standard errors and reduces statistical power, we refrained from using this modeling strategy. Still, as robustness checks we estimated the following two models, guided as much as possible by theory:

1. We interacted power with the following variables: (a) Male (given that males are usually more corrupt that females, Swamy, Knack, Lee, \& Azfar, 2001), (b) age (older individuals usually behave in a wiser and more socially appropriate way, cf. Armantier \& Boly, 2011), (c) extraversion (this factor is quite strongly linked to expression of power and resource control, C. Anderson, John, \& Keltner, 2012), and (d) selfishness (using the behavioral selfishness measure, because theoretically, those who are more selfish may be more prone to be corrupt when having the opportunity to do so). A joint Wald for these interactions was nonsignificant, $\chi^{2}(4)=6.32, p>.10$. 
2. Following the above model, instead of interacting behavioral selfishness with power, we interacted the latent intercept indicating initial level of corruption, which is an alternative form of selfishness, with power. For the estimation procedure we use the LMS method for interactions involving latent variables (Klein \& Moosbrugger, 2000). Again, results were not significant for these interactions, $\chi^{2}(4)=1.61, p>.10$.

\section{Discussion}

The results of our experiments suggest that both the situation and the person predict corruption. As expected, power affects individuals in a way that makes them behave antisocially. Leaders who received additional power and more discretionary choices, whether in one-shot decisions or in repeated choices over time, were more likely to profit from their power and in the case of Study 2 to violate the very social norms to which they had subscribed. As concerns Study 2 , even though the leaders, both in the low and high power condition, had knowledge of what constituted the social norm in terms of payouts, those with more power exercised more antisocial decisions and this presumably due to the psychological mechanisms we described. It seems that individuals given power somehow become inoculated against the psychological costs incurred for violating social norms and likely to benefit themselves while destroying public wealth.

Our results have several important consequences regarding both situational and individual-level antecedents of corruption. With respect to the situational aspects, there are implications for the design of leader governance systems. Organizations should limit leader discretion and keep leaders in check; leaders have many ways in which they can profit from their power including what may seem to be innocuous ways (Core, Holthausen, \& Larcker, 1999). Apart from installing adequate governance mechanisms, perhaps future research should identify ways in which leaders can be made more aware of the great harm they can potentially cause when 
having been enticed by power; there are no studies of which we are aware that have investigated this possibility. Moreover evidence that ethics instruction can induce ethical decision making is rather scant (Waples, Antes, Murphy, Connelly, \& Mumford, 2009), which suggests that it is imperative that future efforts focus more in the mechanisms that engender corruption and how it can be avoided via governance, training, or selection.

As concerns selection, our results also yield important insights on the "person" component. Although honesty and behavioral selfishness predicted initial level of antisocial behavior (negatively and positively respectively), honesty did not shield leaders from corruption. This result, coupled with the findings regarding norm violation per se, shows how tempting power is and how it blinds individuals from doing what is socially appropriate. These results show that even those who have a disposition to be honest and who declared that leaders should not violate social norms, succumbed to the corruptive effects of power. The testosterone results are particularly interesting given that hormones levels can be objectively measured; that we find more corruption when power and testosterone are both high adds some fresh light onto the fact that testosterone's effects should be examined from a situationist perspective too.

Several personality variables also did predict average corruption levels across the high and low power groups; as mentioned, we are hesitant in interpreting these main effects because they include both a time and power component, which can only definitely be teased-out by interacting these variables with power. Nonetheless, future research using larger samples should look into which individual differences predict corruption bearing in mind that it is possible that some of these variables exhibit a double-edged predictive validity with respect to (a) emergence as a leader, and (b) corruption when occupying the role of leader-(see discussion on the positive and negative effects of "bright" and "dark" traits, Judge, et al., 2009). Should individual differences operate in such a manner, institutions might need to walk a fine line in balancing 
leader individual differences that are required to "rally the troops" with governance mechanisms that can keep the "fox out of the henhouse."

\section{Limitations and suggestions for future research}

There are several unique and important aspects in our findings; however, there are some limitations that should temper our conclusions. Specifically, we looked only at one aspect of leader decision making (i.e., regarding distribution of payouts) and one particular power manipulation in a laboratory setting. Although results from industrial-organizational (or organizational-behavior) type laboratory studies such as ours should readily translate to practice (C. A. Anderson, Lindsay, \& Bushman, 1999; Mitchell, 2012), future studies should attempt to manipulate power in field settings.

Although we measured the big-six personality factors in addition to intelligence and behavioral selfishness, there may be other factors like narcissism, Machiavellianism, or psychopathy, which we did not measure and which may predict corruption. Although they would not change the effect we have found for power (given that we manipulated it), including such factors could provide a more complete explanation of possible individual difference effects (note, though, that their predictive power may be limited because they overlap much with the HEXACO factors, see Lee \& Ashton, 2005).

As for our power manipulation within leaders (Study 2), we changed the options available to the leader with respect to a particular interpersonal power dynamic (i.e., the power relation the leader had with his or her first follower). Although we held constant the ratio of leader gains to follower losses across the power manipulations, future research should also examine how increased power affects decision making outside a particular interpersonal power dynamic. The idea would be to observe a constant relation between a leader and a follower having stable options (i.e., the options available to the leader in this particular relation would be identical 
across all power levels and are never altered). The leader's power could then be increased by providing the leader with additional followers and options outside of the initial relationship. This setup would allow studying whether more power induces leaders to change their behavior too within a well-defined and constant relation to a particular follower.

Additionally, by keeping constant leader gains and the ratio of leader gains to follower losses, with increasing power leaders "spread" less harm to subordinates when invoking an antisocial choice. For example, as concerns Study 2, when leaders had baseline power, invoking the antisocial decision increased their payoffs by 50 points and decreased the payoff of one follower by 60 . However, in the medium power condition the decrease to each of three followers was 20 (though the harm to the public good is the same as in the baseline condition $20 * 3=60$ ). Thus, it is possible that leaders think that they are doing less individual harm to each follower, which they veritably are, even though they hurt the public good in the same way. Still, our manipulation does have a real-world analog; when leaders raid taxpayer coffers, the impact to each citizen (i.e., money stolen per capita) is obviously small, yet the effect on the public good on the whole can be colossal.

An alternative manipulation in our games could have been instead to keep the follower losses constant, but this would have implied that the increase in the number of followers would have been accompanied with greater leader monetary gains. Doing so would confound the effect of having more followers with the effect of being able to gain more money. Thus, we believe that our manipulation is the better of the two options, particularly because we can test for the effect of having more followers in an unconfounded manner. Future research should nonetheless investigate other types of leader gain to follower loss tradeoffs crossed with impact on others, to determine how leader behavior is altered by power. 
Finally, although leaders can have complete discretion at their disposal, most leaders consider the likelihood of getting caught prior to taking an antisocial decision (see Mazar \& Ariely, 2006). Future research should include some of these parameters in more complex games (e.g., wherein leaders are informed of a likelihood of being caught, which if occurs, entails heavy losses on the leader's payouts); additional parameters to include could be social interactions (cf. Hogg \& Reid, 2001). Finally, although we did increase power levels within subjects in the second study, our design did not incorporate how power is developed and cascades in organizations (Fiol, O'Connor, \& Aguinis, 2001), as well as the dynamics of how power is lost and gained (see Fehr, Herz, \& Wilkening, 2013; Jordan, Sivanathan, \& Galinsky, 2011; Sivanathan, Pillutla, \& Murnighan, 2008).

\section{Conclusion}

Leaders in business and political settings - and those who try to keep them in checkmust constantly ponder how much power and discretion top-level leaders should have. Increasing controls on leaders certainly engender costs and may slow down decision making; however, the price of governance mechanisms and its effects on outcomes might be a smaller price to pay as compared to the cost of corruption. Finding the balance would be difficult. However, as our results show, even those who were honest and had mostly socially-acceptable attitudes at the moment of their accession to a position of leadership rather easily changed their moral perspectives once they got a taste of power.

To conclude, Acton was partially right. Corruption depends on power. However, corruption depends on the person too. We hope that future research sheds more light on these two routes to corruption because societies need their leaders to exercise power in moral ways. In the meantime, our results suggest that organizations should limit how much leaders can drink from the seductive chalice of power. 


\section{References:}

Acton, J. E. E. D. A., \& Himmelfarb, G. (1948). Essays on freedom and power. Boston: Beacon Press.

Aiken, L. S., \& West, S. G. (1991). Multiple Regression: Testing and Interpreting Interactions. Newbury Park, CA: Sage Publications.

Anand, V., Ashforth, B. E., \& Joshi, M. (2005). Business as usual: The acceptance and perpetuation of corruption in organizations. Academy of Management Executive, 19(4), 923.

Anderson, C., John, O. P., \& Keltner, D. (2012). The Personal Sense of Power. Journal of Personality, 80(2), 313-344.

Anderson, C. A., Lindsay, J. J., \& Bushman, B. J. (1999). Research in Psychological Laboratory: Truth or Triviality? Current Directions in Psychological Science, 8(1), 3-9.

Antonakis, J., Bendahan, S., Jacquart, P., \& Lalive, R. (2010). On making causal claims: A review and recommendations. The Leadership Quarterly, 21(6), 1086-1120.

Antonakis, J., Day, D. V., \& Schyns, B. (2012). Leadership and individual differences: At the cusp of a renaissance. The Leadership Quarterly, 23(4), 643-650.

Armantier, O., \& Boly, A. (2011). A controlled field experiment on corruption. European Economic Review, 55(8), 1072-1082.

Ashforth, B. E., \& Anand, V. (2003). The normalization of corruption in organizations. Research in Organizational Behavior, 25, 1-52.

Bargh, J. A., Raymond, P., Pryer, J. B., \& Strack, F. (1995). Attractiveness of the underling: An automatic power-sex association and its consequences for sexual harassment and aggression. Journal of Personality and Social Psychology, 68(5), 768-781.

Barrick, M. R., \& Mount, M. K. (1993). Autonomy as a Moderator of the Relationships between the Big 5 Personality Dimensions and Job-Performance. Journal of Applied Psychology, 78(1), 111-118.

Bluedorn, A. C., \& Jaussi, K. S. (2008). Leaders, followers, and time. The Leadership Quarterly, 19(6), 654-668.

Bos, P. A., Terburg, D., \& van Honk, J. (2010). Testosterone decreases trust in socially naive humans. Proceedings of the National Academy of Sciences of the United States of America, 107(22), 9991-9995.

Bouchard, T. J., \& Loehlin, J. C. (2001). Genes, evolution, and personality. Behavior Genetics, 31(3), 243-273.

Bouchard, T. J., \& McGue, M. (2003). Genetic and environmental influences on human psychological differences. Journal of Neurobiology, 54(1), 4-45.

Brief, A. P., Buttram, R. T., \& Dukerich, J. M. (2001). Collective corruption in the corporate world: Toward a process model. In M. E. Turner (Ed.), Groups at work: Theory and research (pp. 471-499). Mahwah, NJ: Lawrence Erlbaum.

Chan, D. (1998). The Conceptualization and Analysis of Change Over Time: An Integrative Approach Incorporating Longitudinal Mean and Covariance Structures Analysis (LMACS) and Multiple Indicator Latent Growth Modeling (MLGM). Organizational Research Methods, 1(4), 421-483.

Chen, S., Lee-Chai, A. Y., \& Bargh, J. A. (2001). Relationship orientation as a moderator of the effects of social power. Journal of Personality and Social Psychology, 80(2), 173-187. 
Core, J. E., Holthausen, R. W., \& Larcker, D. F. (1999). Corporate governance, chief executive officer compensation, and firm performance. Journal of Financial Economics, 51(3), 371406.

Cox, D. R., \& Snell, E. J. (1989). Analysis of binary data (2nd ed.). London ; New York: Chapman and Hall.

Dabbs, J. M., \& Dabbs, M. G. (2000). Heroes, rogues, and lovers: Testosterone and behavior. New York: McGraw-Hill.

DeCelles, K. A., DeRue, D. S., Margolis, J. D., \& Ceranic, T. L. (2012). Does Power Corrupt or Enable? When and Why Power Facilitates Self-Interested Behavior. Journal of Applied Psychology, 97(3), 681-689.

Duncan, T. E., Duncan, S. C., \& Strycker, L. A. (2006). An introduction to latent variable growth curve modeling: Concepts, issues, and applications (2nd ed.). Mahwah, N.J.: Lawrence Erlbaum.

Epitropaki, O., \& Martin, R. (2004). Implicit leadership theories in applied settings: Factor structure, generalizability, and stability over time. Journal of Applied Psychology, 89(2), 293-310.

Etzioni, A. (1964). Modern organizations. Englewood Cliffs, New Jersey: Prentice-Hall.

Fast, N. J., Sivanathan, N., Mayer, N. D., \& Galinsky, A. D. (2012). Power and overconfident decision-making. Organizational Behavior and Human Decision Processes, 117(2), 249260.

Fehr, E., Herz, H., \& Wilkening, T. (2013). The lure of authority: Motivation and incentive effects of power. The American Economic Review, 103 1325-1359.

Finkelstein, S. (1992). Power in top management teams: Dimensions, measurement, and validation. Academy of Management Journal, 35(3), 505-538.

Fiol, C. M., O'Connor, E. J., \& Aguinis, H. (2001). All for one and one for all? The development and transfer of power across organizational levels. Academy of Management Review, 26(2), 224-242.

Fischbacher, U. (2007). z-Tree: Zurich toolbox for ready-made economic experiments. Experimental Economics, 10(2), 171-178.

Fiske, S. T. (1993). Controlling Other People: The Impact of Power on Stereotyping. American Psychologist, 48(6), 621-628.

Flynn, F. J., Gruenfeld, D., Molm, L. D., \& Polzer, J. T. (2011). Social Psychological Perspectives on Power in Organizations. Administrative Science Quarterly, 56(4), 495 500.

French, J. R. P., \& Raven, B. H. (1968). The bases of social power. In D. Cartwright \& A. F. Zander (Eds.), Group dynamics: Research and theory (3rd ed., pp. 259-269). New York: Harper \& Row.

Galinsky, A. D., Magee, J. C., Inesi, M. E., \& Gruenfeld, D. H. (2006). Power and perspectives not taken. Psychological Science, 17(12), 1068-1074.

Gino, F., Ayal, S., \& Ariely, D. (2009). Contagion and Differentiation in Unethical Behavior: The Effect of One Bad Apple on the Barrel. Psychological Science, 20(3), 393-398.

Goodwin, S. A., Gubin, A., Fiske, S. T., \& Yzerbyt, V. Y. (2000). Power Can Bias Impression Processes: Stereotyping Subordinates by Default and by Design. Group Processes \& Intergroup Relations, 3(3), 227-256.

Goodwin, S. A., Operario, D., \& Fiske, S. T. (1998). Situational Power and Interpersonal Dominance Facilitate Bias and Inequality. Journal of Social Issues, 54(4), 677-698. 
Guinote, A., Willis, G. B., \& Martellotta, C. (2010). Social power increases implicit prejudice. Journal of Experimental Social Psychology, 46(2), 299-307.

Handa, R. J., Burgess, L. H., Kerr, J. E., \& O'Keefe, J. A. (1994). Gonadal Steroid Hormone Receptors and Sex Differences in the Hypothalamo-Pituitary-Adrenal Axis. Hormones and Behavior, 28(4), 464-476.

Harris, J. A., Vernon, P. A., \& Boomsma, D. I. (1998). The heritability of testosterone: A study of Dutch adolescent twins and their parents. Behavior Genetics, 28(3), 165-171.

Heckman, J. J. (1979). Sample Selection Bias as a Specification Error. Econometrica, 47(1), 153161.

Hogg, M. A., \& Reid, S. A. (2001). Social identity, leadership, and power. In A. Y. Lee-Chai \& J. A. Bargh (Eds.), The use and abuse of power: Multiple perspectives on the causes of corruption (pp. 159-180). Philadelphia: Psychology Press.

House, R. J., Spangler, W. D., \& Woycke, J. (1991). Personality and charisma and the U.S. presidency: A psychological theory of leader effectiveness. Administrative Science Quarterly, 36, 364-396.

IBL International. (2008). Saliva Diagnostics. Hamburg, Germany.

Jones, B. F., \& Olken, B. A. (2005). Do leaders matter? National leadership and growth since World War II. Quarterly Journal of Economics, 835-864.

Jordan, J., Sivanathan, N., \& Galinsky, A. D. (2011). Something to Lose and Nothing to Gain: The Role of Stress in the Interactive Effect of Power and Stability on Risk Taking. Administrative Science Quarterly, 56(4), 530-558.

Judge, T. A., Bono, J. E., Ilies, R., \& Gerhardt, M. W. (2002). Personality and leadership: A qualitative and quantitative review. Journal of Applied Psychology, 87(4), 765-780.

Judge, T. A., LePine, J. A., \& Rich, B. L. (2006). Loving yourself abundantly: Relationship of the narcissistic personality to self- and other perceptions of workplace deviance, leadership, and task and contextual performance. Journal of Applied Psychology, 91(4), 762-776.

Judge, T. A., \& Piccolo, R. F. (2004). Transformational and transactional leadership: A metaanalytic test of their relative validity. Journal of Applied Psychology, 89(5), 755-768.

Judge, T. A., Piccolo, R. F., \& Kosalka, T. (2009). The bright and dark sides of leader traits: A review and theoretical extension of the leader trait paradigm. The Leadership Quarterly, 20(6), 855-875.

Kahneman, D., Knetsch, J. L., \& Thaler, R. H. (1986). Fairness and the Assumptions of Economics. Journal of Business, 59(4), S285-S300.

Keltner, D., Gruenfeld, D. H., \& Anderson, C. (2003). Power, approach, and inhibition. Psychological Review, 110(2), 265-284.

Kenrick, D. T., \& Funder, D. C. (1988). Profiting from controversy: Lessons from the personsituation debate. American Psychologist, 43(1), 23-34.

Keppel, G., \& Wickens, T. D. (2004). Design and Analysis: A researcher's handbook. Upper Saddle River, NJ: Pearson.

Kessler, J. B., \& Leider, S. (2012). Norms and Contracting. Management Science, 58(1), 62-77.

Kipnis, D. (1972). Does Power corrupt? Journal of Personality and Social Psychology, 24(1), 3341.

Klein, A., \& Moosbrugger, H. (2000). Maximum likelihood estimation of latent interaction effects with the LMS method. Psychometrika, 65(4), 457-474.

Koopman, P. A. R. (1984). Confidence intervals for the ratio of two binomial proportions. Biometrics, 40(2), 513-517. 
Krupka, E. L., \& Weber, R. A. (2013). Identifying social norms using coordination games: Why does dictator game sharing vary? . Journal of the European Economic Association, 11(3), 495-524.

Lee, K., \& Ashton, M. C. (2004). Psychometric properties of the HEXACO personality inventory. Multivariate Behavioral Research, 39(2), 329-358.

Lee, K., \& Ashton, M. C. (2005). Psychopathy, Machiavellianism, and Narcissism in the FiveFactor Model and the HEXACO model of personality structure. Personality and Individual Differences, 38(7), 1571-1582.

Lee, K., \& Ashton, M. C. (2008). The HEXACO Personality Factors in the Indigenous Personality Lexicons of English and 11 Other Languages. Journal of Personality, 76(5), 1001-1053.

Lee, K., Ashton, M. C., \& de Vries, R. E. (2005). Predicting Workplace delinquency and integrity with the HEXACO and five-factor models of personality structure. Human Performance, 18(2), 179-197.

Lee, K., Ashton, M. C., Morrison, D. L., Cordery, J., \& Dunlop, P. D. (2008). Predicting integrity with the HEXACO personality model: Use of self- and observer reports. Journal of Occupational and Organizational Psychology, 81, 147-167.

Liening, S. H., Stanton, S. J., Saini, E. K., \& Schultheiss, O. C. (2010). Salivary testosterone, cortisol, and progesterone: Two-week stability, interhormone correlations, and effects of time of day, menstrual cycle, and oral contraceptive use on steroid hormone levels. Physiology \& Behavior, 99(1), 8-16.

Loviscky, G. E., Trevino, L. K., \& Jacobs, R. R. (2007). Assessing managers' ethical decisionmaking: An objective measure of managerial moral judgment. Journal of Business Ethics, 73(3), 263-285.

Lowe, K. B., Kroeck, K. G., \& Sivasubramaniam, N. (1996). Effectiveness correlates of transformational and transactional leadership: A meta-analytic review of the MLQ literature. The Leadership Quarterly, 7(3), 385-425.

Magee, J. C., \& Galinsky, A. D. (2008). Social Hierarchy: The Self-Reinforcing Nature of Power and Status. Academy of Management Annals, 2, 351-398.

Manz, C. C., Anand, V., Joshi, M., \& Manz, K. P. (2008). Emerging paradoxes in executive leadership: A theoretical interpretation of the tensions between corruption and virtuous values. The Leadership Quarterly, 19(3), 385-392.

Mauro, P. (1995). Corruption and growth. Quarterly Journal of Economics, 110(3), 681-712.

Maxwell, S. E., Cole, D. A., Arvey, R. D., \& Salas, E. (1991). A comparison of methods for increasing power in randomized between-subjects designs. Psychological Bulletin, $110(2), 328-337$.

Mazar, N., \& Ariely, D. (2006). Dishonesty in Everyday Life and Its Policy Implications. Journal of Public Policy \& Marketing, 25(1), 117-126.

Mazur, A., \& Booth, A. (2014). Testosterone is related to deviance in male army veterans, but relationships are not moderated by cortisol. Biological Psychology, 96(0), 72-76.

Mead, N. L., Baumeister, R. F., Gino, F., Schweitzer, M. E., \& Ariely, D. (2009). Too tired to tell the truth: Self-control resource depletion and dishonesty. Journal of Experimental Social Psychology, 45(3), 594-597.

Mischel, W. (1977). The interaction of person and situation. In D. Magnusson \& D. Endler (Eds.), Personality at the crossroads: Current issues in interactional psychology (pp. 333352). Hillsdale, NJ: Lawrence Erlbaum associates, Publishers. 
Mitchell, G. (2012). Revisiting Truth or Triviality. Perspectives on Psychological Science, 7(2), 109-117.

Muthén, L. K., \& Muthén, B. O. (2012). Mplus user's guide (7th ed.). Los Angeles, CA: Muthén \& Muthén.

The Oxford English Dictionary Online. (2000). Oxford: Oxford University Press.

Palanski, M. E., \& Yammarino, F. J. (2009). Integrity and leadership: A multi-level conceptual framework. Leadership Quarterly, 20(3), 405-420.

Pearce, C. L., Manz, C. C., \& Sims Jr, H. P. (2008). The roles of vertical and shared leadership in the enactment of executive corruption: Implications for research and practice. The Leadership Quarterly, 19(3), 353-359.

Piff, P. K., Stancato, D. M., Cote, S., Mendoza-Denton, R., \& Keltner, D. (2012). Higher social class predicts increased unethical behavior. Proceedings of the National Academy of Sciences of the United States of America, 109(11), 4086-4091.

Plato, \& Jowett, B. (1901). The republic of Plato; an ideal commonwealth (Rev. ed.). New York: The Colonial Press.

Podsakoff, P. M., MacKenzie, S. B., Lee, J.-Y., \& Podsakoff, N. P. (2003). Common Method Biases in Behavioral Research: A Critical Review of the Literature and Recommended Remedies. Journal of Applied Psychology, 89(5), 879-903.

Podsakoff, P. M., MacKenzie, S. B., \& Podsakoff, N. P. (2012). Sources of Method Bias in Social Science Research and Recommendations on How to Control It. Annual Review of Psychology, 63(1), 539-569.

Potrafke, N. (2012). Intelligence and corruption. Economics Letters, 114(1), 109-112.

Ring, H. J. Z., Lessov, C. N., Reed, T., Marcus, R., Holloway, L., Swan, G. E., et al. (2005). Heritability of plasma sex hormones and hormone binding globulin in adult male twins. Journal of Clinical Endocrinology and Metabolism, 90(6), 3653-3658.

Ronay, R., \& Carney, D. R. (2013). Testosterone's Negative Relationship With Empathic Accuracy and Perceived Leadership Ability. Social Psychological and Personality Science, 4(1), 92-99.

Rowe, R., Maughan, B., Worthman, C. M., Costello, E. J., \& Angold, A. (2004). Testosterone, antisocial behavior, and social dominance in boys: pubertal development and biosocial interaction. Biological Psychiatry, 55(5), 546-552.

Sapienza, P., Zingales, L., \& Maestripieri, D. (2009). Gender differences in financial risk aversion and career choices are affected by testosterone. Proceedings of the National Academy of Sciences of the United States of America, 106(36), 15268-15273.

Sapienza, P., Zingales, L., \& Maestripieri, D. (2010). Reply to Joel and Tarrasch: On the relationship between testosterone, gender, financial risk aversion, and career choices. Proceedings of the National Academy of Sciences of the United States of America, 107(5), E20-E20.

Satorra, A., \& Bentler, P. M. (2001). A scaled difference chi-square test statistic for moment structure analysis. Psychometrika, 66(4), 507-514.

Schein, E. H. (1990). Organizational culture. American Psychologist, 45(2), 109-119.

Schein, E. H. (1992). Organizational culture and leadership (2nd ed.). San Francisco: JosseyBass.

Sellers, J. G., Mehl, M. R., \& Josephs, R. A. (2007). Hormones and personality: Testosterone as a marker of individual differences. Journal of Research in Personality, 41(1), 126-138.

Shamir, B. (2011). Leadership takes time: Some implications of (not) taking time seriously in leadership research. The Leadership Quarterly, 22(2), 307-315. 
Sherman, L. W. (1980). Three Models of Organizational Corruption in Agencies of Social Control. Social Problems, 27(4), 478-491.

Simons, T., Palanski, M., \& Trevino, L. (2013). Toward a broader - but still rigorous - definition of leader integrity: Commentary. Leadership Quarterly, 24(3), 391-394.

Sivanathan, N., Pillutla, M. M., \& Murnighan, J. K. (2008). Power gained, power lost. Organizational Behavior and Human Decision Processes, 105(2), 135-146.

Sturm, R. E., \& Antonakis, J. (2015). Interpersonal power: A review, critique, and research agenda. Journal of Management, http://dx.doi.org/10.1177/0149206314555769

Swamy, A., Knack, S., Lee, Y., \& Azfar, O. (2001). Gender and corruption. Journal of Development Economics, 64(1), 25-55.

Tost, L. P., Gino, F., \& Larrick, R. P. (2012). Power, competitiveness, and advice taking: Why the powerful don't listen. Organizational Behavior and Human Decision Processes, 117(1), 53-65.

Trevino, L. K. (1986). Ethical Decision Making in Organizations: A Person-Situation Interactionist Model. The Academy of Management Review, 11(3), 601-617.

Turner, N., Barling, J., Epitropaki, O., Butcher, V., \& Milner, C. (2002). Transformational leadership and moral reasoning. Journal of Applied Psychology, 2(87), 304-311.

Tversky, A., \& Kahneman, D. (1974). Judgment under Uncertainty: Heuristics and Biases. Science, 185(4157), 1124-1131.

van Honk, J., Schutter, D. J., Bos, P. A., Kruijt, A.-W., Lentjes, E. G., \& Baron-Cohen, S. (2011). Testosterone administration impairs cognitive empathy in women depending on secondto-fourth digit ratio. Proceedings of the National Academy of Sciences, 108(8), 34483452.

van Honk, J., Schutter, D. J. L. G., Hermans, E. J., Putman, P., Tuiten, A., \& Koppeschaar, H. (2004). Testosterone shifts the balance between sensitivity for punishment and reward in healthy young women. Psychoneuroendocrinology, 29(7), 937-943.

van Kleef, G. A., Oveis, C., van der Lowe, I., LuoKogan, A., Goetz, J., \& Keltner, D. (2008). Power, Distress, and Compassion: Turning a Blind Eye to the Suffering of Others. Psychological Science, 19(12), 1315-1322.

Waples, E. P., Antes, A. L., Murphy, S. T., Connelly, S., \& Mumford, M. D. (2009). A MetaAnalytic Investigation of Business Ethics Instruction. Journal of Business Ethics, 87(1), 133-151.

Wonderlic. (2002). Wonderlic Personnel Test \& Scholastic Level Exam: User's manual. Libertyville, IL: Wonderlic Personnel Test, Inc.

Wright, N. D., Bahrami, B., Johnson, E., Di Malta, G., Rees, G., Frith, C. D., et al. (in press). Testosterone disrupts human collaboration by increasing egocentric choices. Proceedings of the Royal Society B: Biological Sciences.

Zaccaro, S. J. (2012). Individual differences and leadership: Contributions to a third tipping point. The Leadership Quarterly, 23(4), 718-728.

Zak, P. J., Kurzban, R., Ahmadi, S., Swerdloff, R. S., Park, J., Efremidze, L., et al. (2009). Testosterone Administration Decreases Generosity in the Ultimatum Game. PLoS ONE, 4(12), Article number e8330.

Zizzo, D. J. (2010). Experimenter demand effects in economic experiments. Experimental Economics, 13(1), 75-98. 


\section{Figure 1: How power engenders corruption}

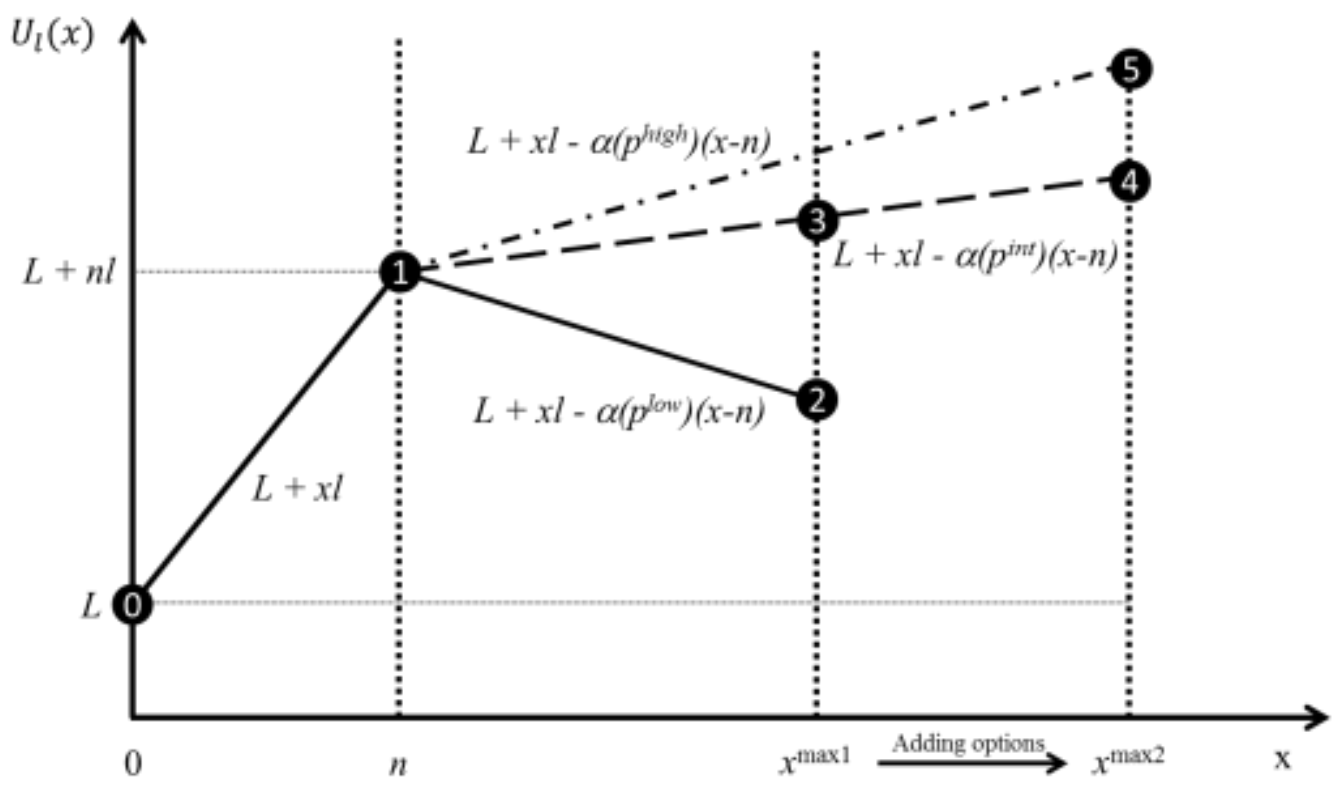

Note: We show how increasing the degree of power can induce a leader to engage in norm-violating and socially inefficient (i.e. corrupt) behavior. As a starting point, assume that the leader has low power $\left(p^{\text {low }}\right)$ and the maximum of $x$ is given by $x^{\max 1}$ (reduced set of options for the leader). As long as $x$ is lower than the social norm $(x<n)$, the leaders utility is given by $U_{l}(x)=L+l x$. In this region the leader's utility is strictly increasing in $x$, because a higher $x$ increases the leader's monetary gains and there is no disutility from violating a social norm (see the increase from Point 0 to Point 1 in the figure). However, if $x$ is increased beyond the social norm $n$, the leader's utility is given by: $U_{l}(x)=L+l x-\alpha\left(p^{l o w}\right)(x-n)$. The low power leader suffers considerably from violating the social norm and the disutility from violating the social norm outweighs the material benefit of increasing $x$ (i.e., $\alpha\left(p^{\text {low }}\right)>l$ ). Thus, increasing $x$ beyond the social norm decreases the leader's utility (from Point 1 to Point 2); this leader's maximal utility is therefore reached at Point 1 (i.e. the optimal choice of this leader is to set $x$ equal to the social norm $n$ ).

Suppose the leader's power increases to an intermediate level (e.g., because additional followers are assigned or the set of options is extended so that the leader can increase $\mathrm{x}$ up to $x^{\max 2}$ ). Our assumption that more powerful leaders suffer less from deviating from social norms (i.e., $\partial \alpha(p) / \partial p<0)$ implies that the disutility from violating the social norm decreases from $\alpha\left(p^{\text {low }}\right)$ to $\alpha\left(p^{\text {int }}\right)$. As per the figure, this decrease is large enough so that now the monetary benefit from increasing $x$ dominates the disutility from violating the social norm (i.e., $\left.\alpha\left(p^{\text {int }}\right)<l\right)$. As a consequence, the leader's utility further increases even if the leader violates the social norm (increase from Point 1 to Points 3 and 4). Accordingly, the leader would now increase $x$ up to the maximally possible level ( $x^{\text {max } 1}$ or $x^{\max 2}$, depending on whether the leader's choice set has been extended or not). If a leader's power is further extended by combining the assignment of more followers with an extension of the choice set, the leader's disutility from norm violations decreases further (from $\alpha\left(p^{\text {int }}\right)$ to $\alpha\left(p^{\text {high }}\right)$ ) and the leader benefits even more strongly from increasing $x$ up to the maximum level $x^{\max 2}$ (Point 5). ${ }^{10}$

${ }^{10}$ Our model predicts that both (a) an extension of the choice set alone and (b) a combination of such an extension with an assignment of additional followers induce the leader to increase $x$ up to the maximum level $x^{\max 2}$. This prediction is an artifact of our simplifying assumption that the disutility from a norm violation is proportional to the distance between the leader's choice and the social norm $(x-n)$. Relaxing this assumption by allowing for a nonlinear (convex) relation between the disutility and the distance would give the prediction that the combination of the two power enhancers would lead to higher corruption than the extension of the choice set alone. We do not show this complex version of the model for the sake of expositional clarity. 
Figure 2: Percentage of corrupt decisions as a function of leader power (Study 1)

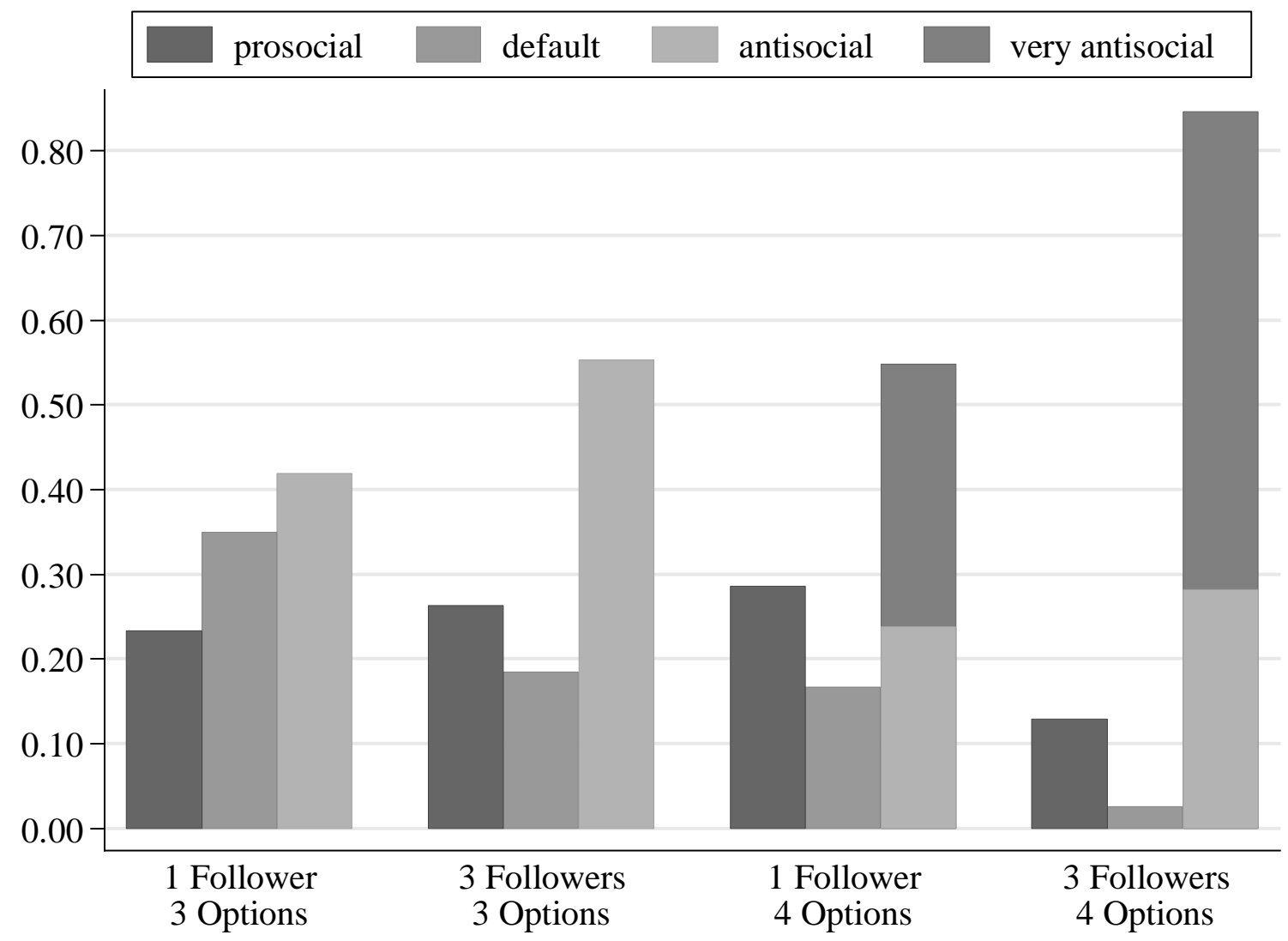

Note, for comparative purposes with the conditions having 3 options, the "very antisocial" bar is stacked on the antisocial bar for the conditions having 4 decision options. 


\section{Figure 3: Summary of the measures and design (Study 2)}

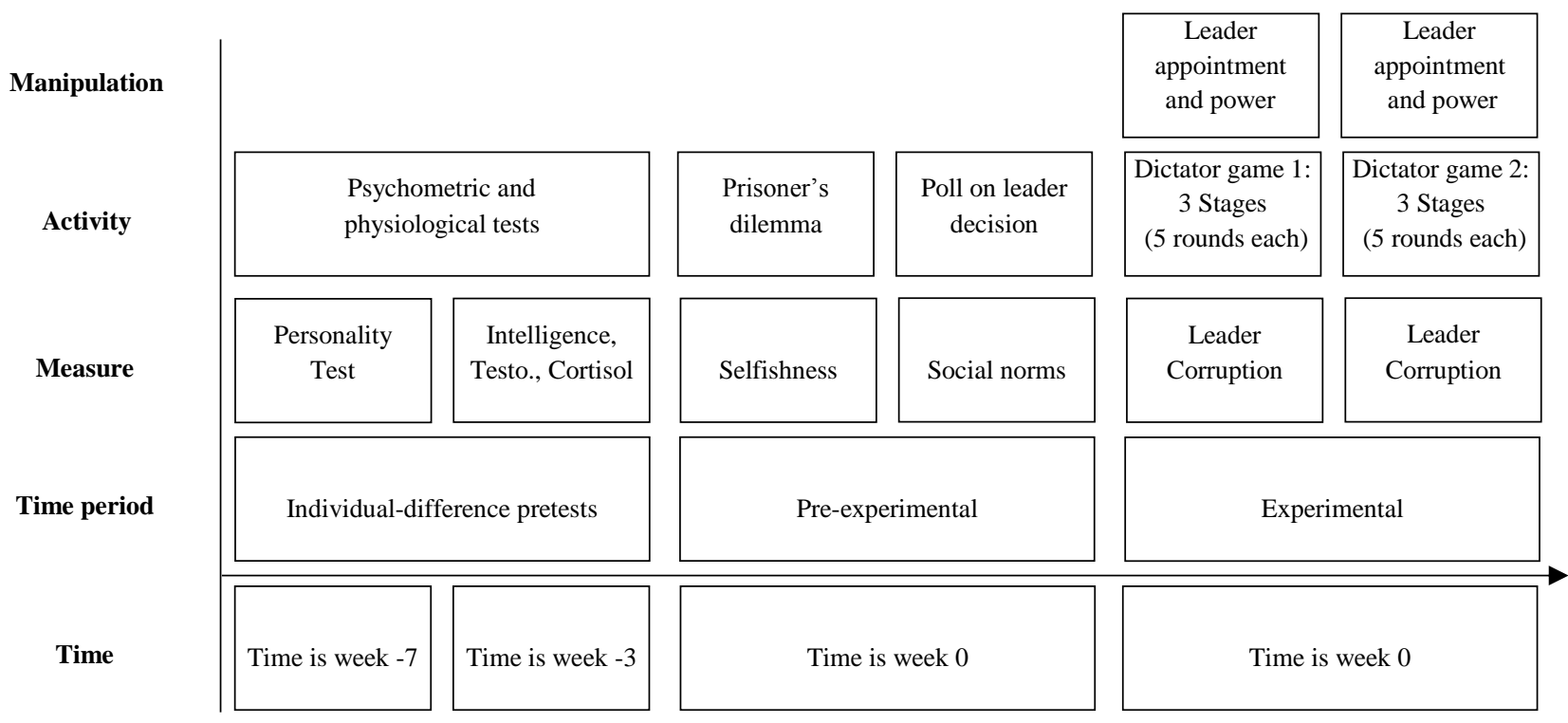

Note: The above summarizes the design of Study 2 in terms of which measures we gathered, how we gathered them, and when we gathered them. Data was gathered over three time periods spanning seven weeks. We first gathered individual difference measures using psychological and physiological tests (i.e., personality, intelligence, hormones). Just prior to the experiment, we measured behavioral selfishness via a prisoner's dilemma having real monetary stakes; we also polled participants about what a responsible leader should do when having complete discretion regarding payouts (to the leader and his or her followers). Thereafter we randomized participants to be leaders ("dictators") or followers. We then randomized leaders to a high or low-power condition in the dictator game, wherein we could observe the decision about payoff allocations taken by the leader. 
Figure 4: Distribution of Time 1 salivary testosterone by sex (Study 2)

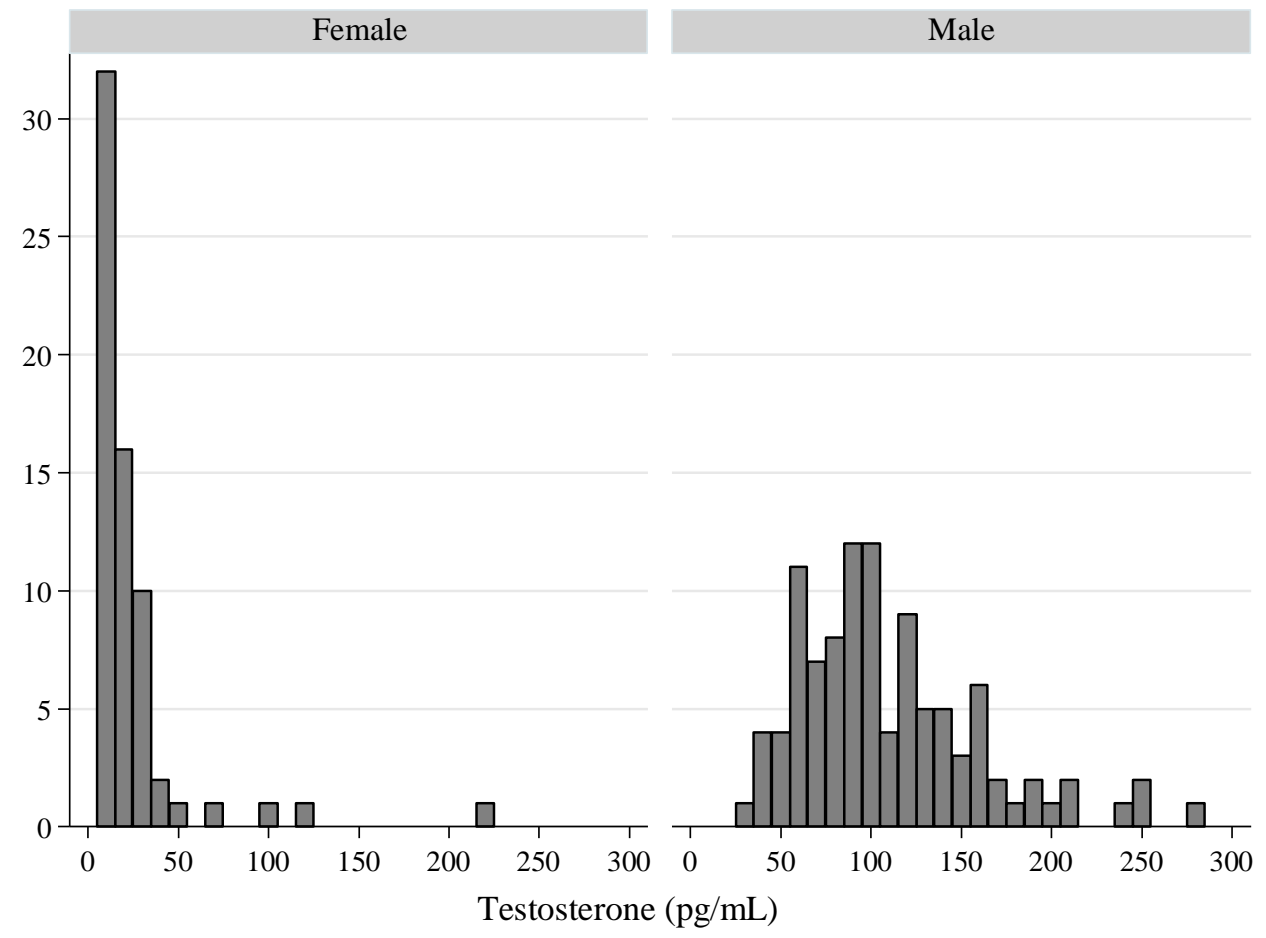

Note: Distribution of salivary testosterone by sex; for presentation purposes, values are rounded up to the nearest multiple of 10 . 


\section{Figure 5: Parameters of the prisoner dilemma's game (i.e., behavioral selfishness measure,}

\section{Study 2)}

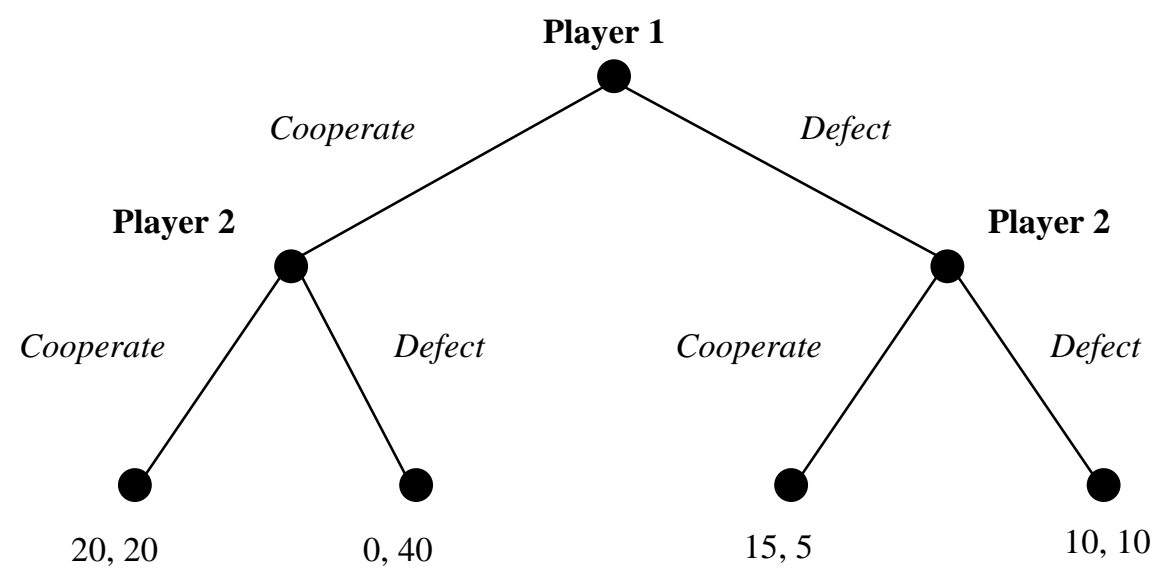

Note: To measure selfishness, participants play a one-shot, sequential prisoners' dilemma with real monetary stakes. We elicited second mover responses using the strategy method; that is, participants made choices in both the role of first or second mover before knowing to which role they would be actually assigned (which we randomly determined). The first movers (Player 1) decided whether or not to send their endowment to the second movers (Player 2); if Player 1 transferred his or her endowment to Player 2, this amount would be tripled by the experimenters and given to Player 2. Player 2 then had to decide whether or not to send half of his or her earnings (i.e., the initial endowment plus the transfer from Player 1 if relevant) to the first mover. We used the second mover response to first mover cooperation as a proxy for selfishness (we did not use the first mover decision because this is mostly a proxy of Player 1's belief of the trustworthiness of Player 2). Initial endowment for the players is 10 points $(10$ points $=\$ 3)$.

To see how payout permutations are calculated, suppose Player 1 cooperates by transferring his or her initial 10 points; these points are tripled thus giving Player 2 a total of 40 points ( 30 points from Player 1 plus Player 2's initial endowment of 10 points). If Player 2 does not cooperate they keep these 40 points and Player 1 gets nothing (in this case, Player 2 is selfish). If Player 2 cooperates they can send half of their total earning back to Player 1 (i.e., 40/2= 20 points), giving both Player 1 and Player 2 each 20 points. The optimal (i.e., selfish) decision is for Player 2 to not cooperate. If both players defect, they both keep their initial endowment of 10 points. If Player 1 defects (sends nothing) and Player 2 cooperates by sending half their endowment (i.e., 10/2=5) to Player 1, the latter has 15 points and the Player 2 only 5 points. 
Figure 6: Corruption of low- and high-power leaders (Study 2)

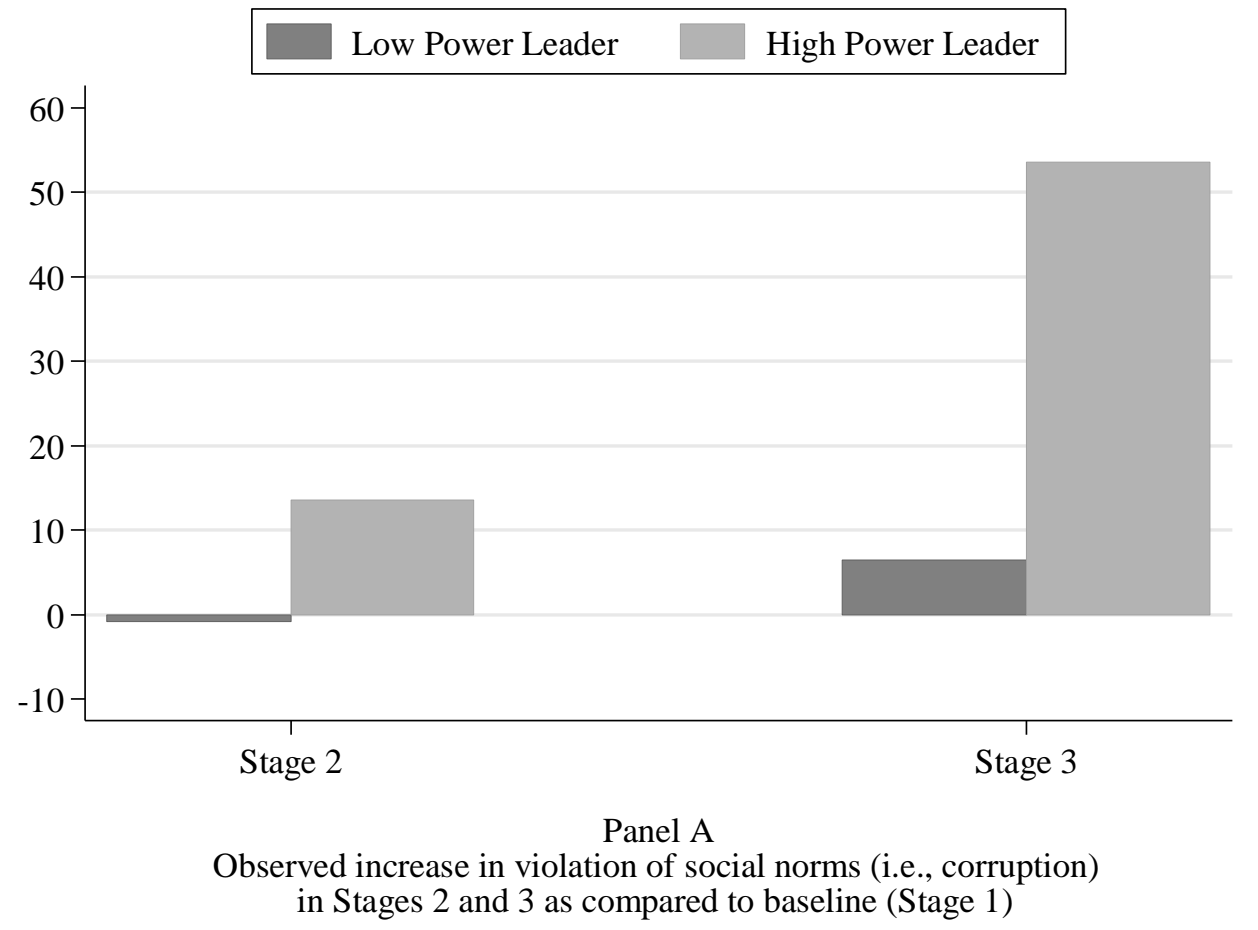


Figure 7: Latent growth curve models (Study 2)

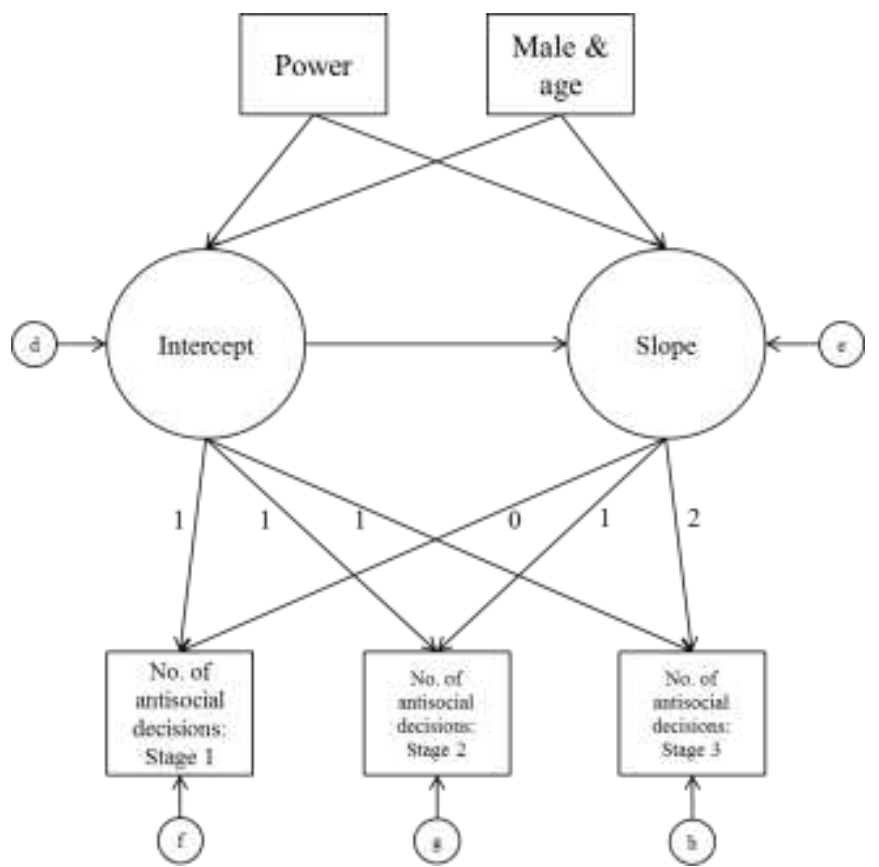

Figure 7A: The simple latent growth curve model

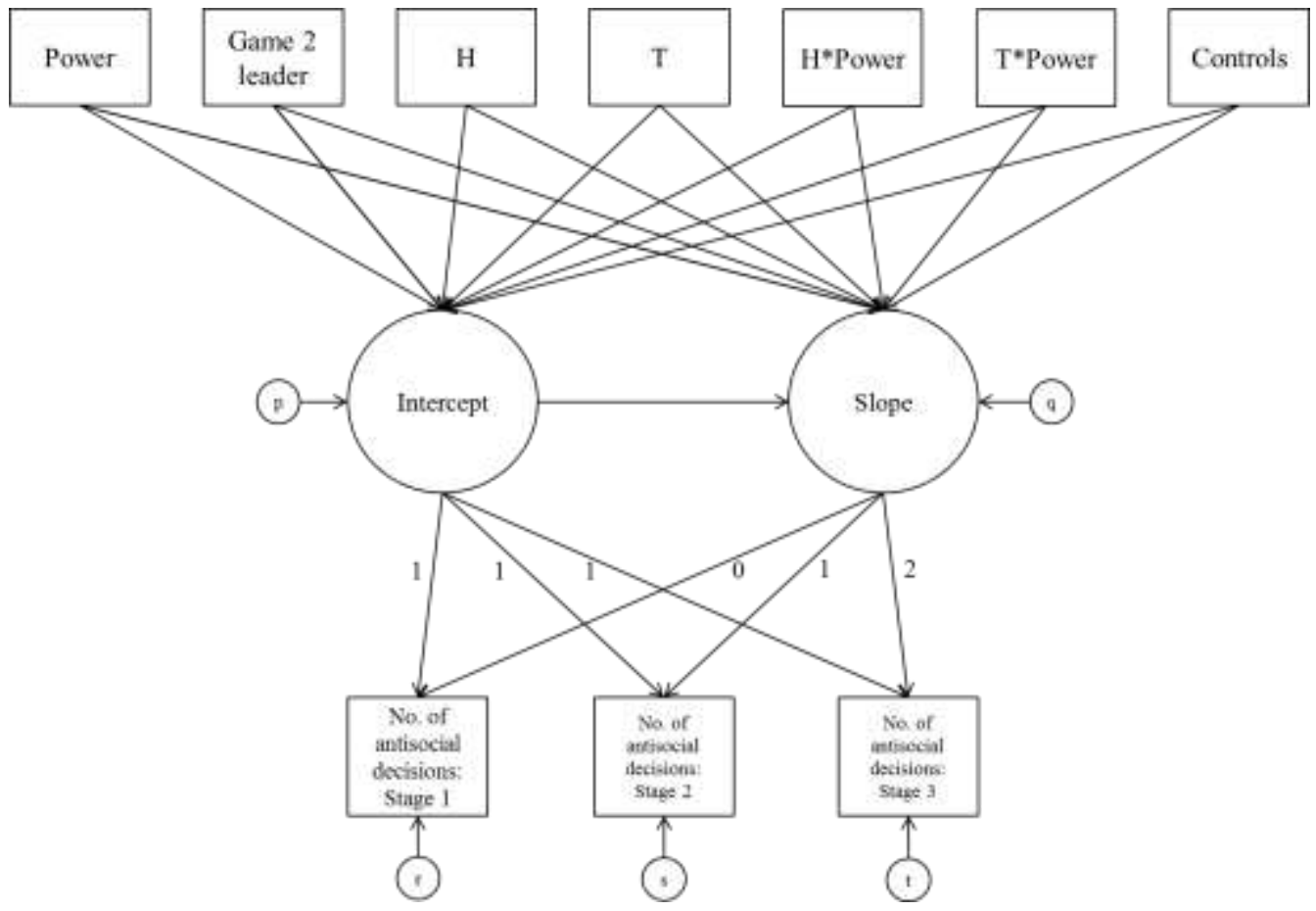

Figure 7B: The latent growth curve model with all covariates and controls

Note: Exogenous variables were allowed to correlate; arrows refer to regression coefficients; Intercept $=$ latent intercept (identified by constraining the coefficients of indicators to 1 , which estimates initial level of antisocial behavior); slope $=$ latent slope (identified by constraining coefficients of indicators to 0,1 , and 2 , which estimates the linear growth in antisocial behavior, i.e., corruption); $\mathrm{H}=$ honesty; $\mathrm{T}=$ testosterone; $d-h$ and $p$ - $t$ refers to disturbances (i.e., errors); Controls $=$ independent effects of all control variables. 
Figure 8: Power-testosterone interaction (Study 2)

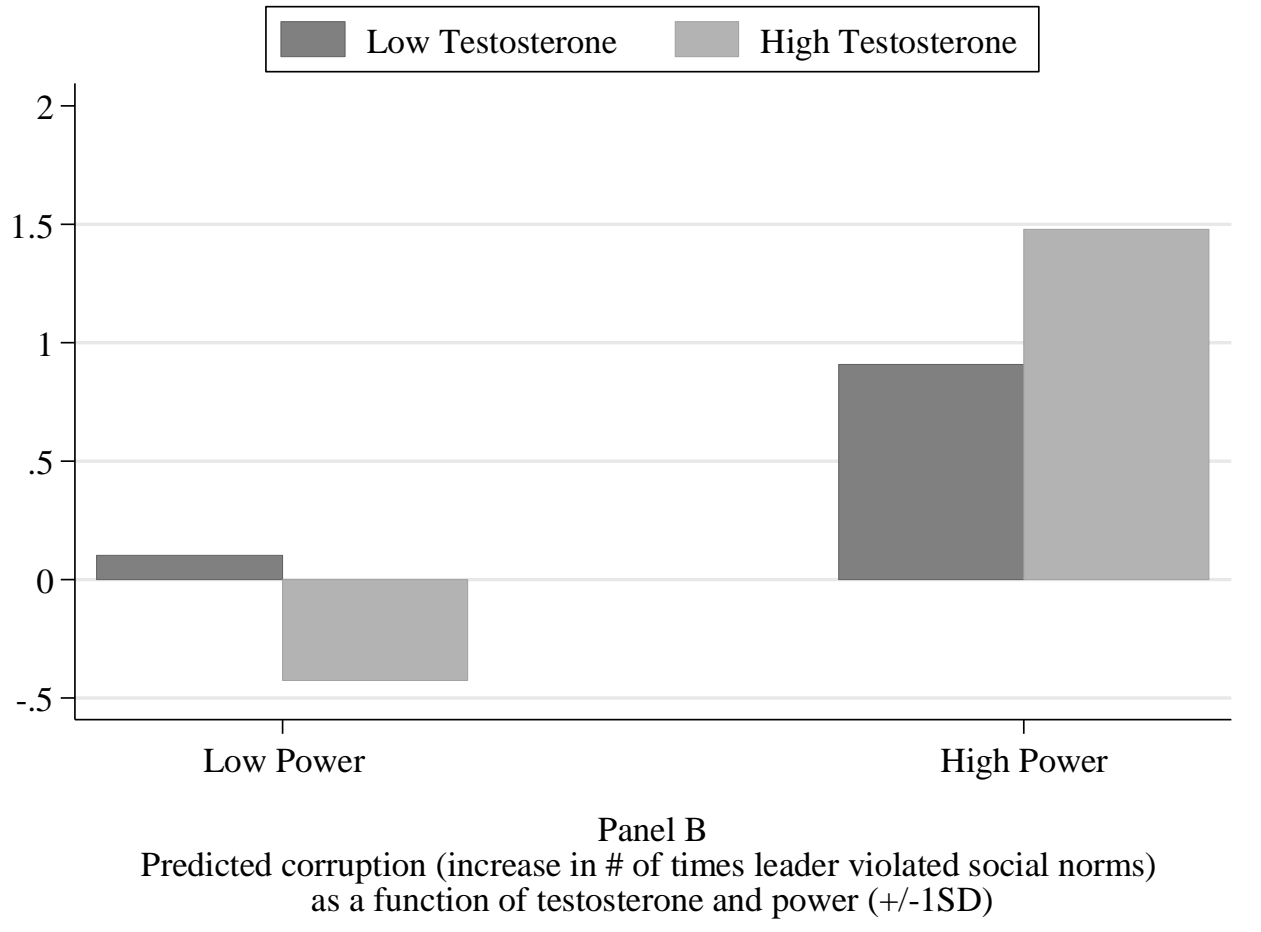




\section{Table 1: Manipulation check for power}

\begin{tabular}{lcc}
\hline & $\begin{array}{c}\text { Power Index } \\
(\mathrm{q} 1, \mathrm{q} 3)\end{array}$ & $\begin{array}{c}\text { Control Question } \\
(\mathrm{q} 2)\end{array}$ \\
\hline \multirow{3}{*}{ Medium power } & $.51^{* *}$ & -.20 \\
& $(2.07)$ & $(.67)$ \\
High power & $1.08^{* * *}$ & -.13 \\
& $(4.04)$ & $(.39)$ \\
Constant & $4.69^{* * *}$ & $4.79^{* * *}$ \\
& $(27.29)$ & $(22.86)$ \\
$R$-square & & .01 \\
& & \\
\hline
\end{tabular}

$n=90 ; * * *<.01,{ }^{* *} p<.05,{ }^{*} p<.10 ; z$ statistics in parentheses; omitted category is baseline (i.e., low) power 
Table 2: Parameters of the Dictator Game (Study 1)

\begin{tabular}{|c|c|c|c|c|c|c|}
\hline \multirow[b]{2}{*}{$\begin{array}{l}\text { Leader's } \\
\text { choice }\end{array}$} & \multicolumn{3}{|c|}{1 Follower, 3 Options } & \multicolumn{3}{|c|}{3 Followers, 3 Option } \\
\hline & $\begin{array}{c}\text { To } \\
\text { Leader }\end{array}$ & $\begin{array}{c}\text { To } \\
\text { 1 Follower }\end{array}$ & $\begin{array}{c}\text { Social } \\
\text { Surplus }\end{array}$ & $\begin{array}{c}\text { To } \\
\text { Leader }\end{array}$ & $\begin{array}{c}\text { To each of } \\
3 \text { Followers }\end{array}$ & $\begin{array}{c}\text { Social } \\
\text { Surplus }\end{array}$ \\
\hline \multirow{3}{*}{$\begin{array}{l}\text { Default } \\
\text { Prosocial } \\
\text { Antisocial }\end{array}$} & 220 & 190 & $220+190=410$ & 220 & 190 & $=220+3 * 190=790$ \\
\hline & 210 & 210 & $210+210=420$ & 210 & 210 & $=210+3 * 210=840$ \\
\hline & 270 & 130 & $270+130=400$ & 270 & 170 & $=270+3 * 170=780$ \\
\hline & \multicolumn{3}{|c|}{1 Follower, 4 Options } & \multicolumn{3}{|c|}{$\underline{3 \text { Followers, } 4 \text { Options }}$} \\
\hline $\begin{array}{l}\text { Leader's } \\
\text { choice }\end{array}$ & $\begin{array}{c}\text { To } \\
\text { Leader }\end{array}$ & $\begin{array}{c}\text { To } \\
\text { 1 Follower }\end{array}$ & $\begin{array}{c}\text { Social } \\
\text { Surplus }\end{array}$ & $\begin{array}{c}\text { To } \\
\text { Leader }\end{array}$ & $\begin{array}{l}\text { To each of } \\
3 \text { Followers }\end{array}$ & $\begin{array}{c}\text { Social } \\
\text { Surplus }\end{array}$ \\
\hline \multirow{4}{*}{$\begin{array}{l}\text { Default } \\
\text { Prosocial } \\
\text { Antisocial } \\
\text { Very Antisocial }\end{array}$} & 220 & 190 & $220+190=410$ & 220 & 190 & $=220+3 * 190=790$ \\
\hline & 210 & 210 & $210+210=420$ & 210 & 210 & $=210+3 * 210=840$ \\
\hline & 270 & 130 & $270+130=400$ & 270 & 170 & $=270+3 * 170=780$ \\
\hline & 370 & 10 & $370+10=380$ & 370 & 130 & $=370+3 * 130=760$ \\
\hline
\end{tabular}

Note: Leaders were placed in one condition only and took one decision only. 100 points $=\$ 5.60$ 


\section{Table 3: Probit regression estimates (Study 1)}

\begin{tabular}{lc}
\hline & $\begin{array}{c}\text { Corruption } \\
\text { (overall) }\end{array}$ \\
\hline Four options & $.56^{* *}$ \\
Three followers & $(2.63)$ \\
Age & $.62^{* *}$ \\
Male & $(2.82)$ \\
& -.11 \\
& $(1.36)$ \\
Constant & .29 \\
& $(1.33)$ \\
& \\
\hline
\end{tabular}

$N=162$; robust $\mathrm{z}$-statistics in parentheses; $* * p<.01,{ }^{*} p<.05$. In the above specification, we controlled for fixed-effects of session (i.e., three sessions). Omitted categories are having three options or one subordinate. Pseudo R-square is based on the Cox-Snell (1989) method. Predicted probabilities for the conditions are reported in the text. 
Table 4: Parameters of the Dictator Game (Study 2)

\begin{tabular}{|c|c|c|c|c|c|c|c|c|c|}
\hline \multirow[b]{2}{*}{$\begin{array}{l}\text { Leader's } \\
\text { choice }\end{array}$} & \multicolumn{3}{|c|}{$\frac{\text { Baseline }}{\underline{\text { Payoffs }}}$} & \multicolumn{3}{|c|}{$\frac{\text { Medium Power }}{\underline{\text { Payoffs }}}$} & \multicolumn{3}{|c|}{$\frac{\text { High Power }}{\underline{\text { Payoffs }}}$} \\
\hline & $\begin{array}{c}\text { To } \\
\text { Leader }\end{array}$ & $\begin{array}{c}\text { To } \\
\text { 1 Follower }\end{array}$ & $\begin{array}{c}\text { Social } \\
\text { Surplus }\end{array}$ & $\begin{array}{c}\text { To } \\
\text { Leader }\end{array}$ & $\begin{array}{c}\text { To each of } \\
3 \text { Followers }\end{array}$ & $\begin{array}{c}\text { Social } \\
\text { Surplus }\end{array}$ & $\begin{array}{c}\text { To } \\
\text { Leader }\end{array}$ & $\begin{array}{l}\text { To each of } \\
3 \text { Followers }\end{array}$ & $\begin{array}{c}\text { Social } \\
\text { Surplus }\end{array}$ \\
\hline Default & 100 & 70 & $100+70=170$ & 100 & 70 & $100+3 * 70=310$ & 100 & 70 & $100+3 * 70=310$ \\
\hline Prosocial & 90 & 90 & $90+90=180$ & 90 & 90 & $90+3 * 90=360$ & 90 & 90 & $90+3 * 90=360$ \\
\hline Antisocial & 150 & 10 & $150+10=160$ & 150 & 50 & $150+3 * 50=300$ & 150 & 50 & $150+3 * 50=300$ \\
\hline Very Antisocial & & & & & & & 250 & 10 & $250+3 * 10=280$ \\
\hline
\end{tabular}

Note: Leaders in the low-power (control) group only had the "Baseline Payoffs" available to choose from for all three stages of the game. The "Medium Power Payoffs" were available to leaders in the high-power (treatment) condition in Stage 2; the "High Power Payoffs" were available to leaders in the high-power condition in Stage 3 only. 100 points $=\$ 2$. Leaders took five decisions over three rounds (thus a total of 15 payoff decisions). 
Table 5: Correlation matrix of key variables (Study 2)

\begin{tabular}{|c|c|c|c|c|c|c|c|c|c|c|c|c|c|c|c|c|c|c|c|c|c|c|}
\hline & & Mean & S.D. & 1 & 2 & 3 & 4 & 5 & 6 & 7 & 8 & 9 & 10 & 11 & 12 & 13 & 14 & 15 & 16 & 17 & 18 & 19 \\
\hline 1 & Corruption Stage 1 & 1.57 & 1.91 & & & & & & & & & & & & & & & & & & & \\
\hline 2 & Corruption Stage 2 & 1.67 & 1.94 & .85 & & & & & & & & & & & & & & & & & & \\
\hline 3 & Corruption Stage 3 & 2.06 & 2.06 & .79 & .80 & & & & & & & & & & & & & & & & & \\
\hline 4 & Behavioral selfishness & .58 & .49 & .38 & .27 & .33 & & & & & & & & & & & & & & & & \\
\hline 5 & Game 2 leader & 1.49 & .50 & .02 & -.09 & -.05 & .09 & & & & & & & & & & & & & & & \\
\hline 6 & Power & .43 & .50 & .17 & .24 & .39 & .07 & -.03 & & & & & & & & & & & & & & \\
\hline 7 & Testosterone $(\mathrm{pg} / \mathrm{mL})$ & 72.06 & 60.30 & .30 & .35 & .37 & .13 & .16 & .09 & & & & & & & & & & & & & \\
\hline 8 & Cortisol (ng/mL) & .41 & .21 & -.11 & -.08 & -.14 & -.04 & .01 & -.12 & .02 & & & & & & & & & & & & \\
\hline 9 & Power*Testosterone & 33.54 & 55.14 & .21 & .32 & .45 & .07 & .03 & .70 & .52 & -.07 & & & & & & & & & & & \\
\hline 10 & Intelligence & 28.33 & 5.16 & .17 & .15 & .14 & .09 & .10 & .06 & .12 & -.13 & .09 & & & & & & & & & & \\
\hline 11 & Honesty & -.03 & .98 & -.30 & -.32 & -.22 & -.22 & .10 & .04 & -.06 & -.05 & .07 & .05 & & & & & & & & & \\
\hline 12 & Emotionality & .02 & 1.02 & -.07 & -.10 & -.04 & .01 & -.07 & .08 & -.05 & -.03 & .08 & -.03 & .13 & & & & & & & & \\
\hline 13 & Extraversion & -.03 & .93 & .03 & .06 & .09 & -.11 & .03 & .04 & .05 & .07 & .00 & .00 & -.10 & -.11 & & & & & & & \\
\hline 14 & Agreeableness & -.10 & 1.01 & -.11 & -.10 & -.05 & -.13 & .11 & .00 & .00 & -.01 & .10 & -.06 & .37 & -.20 & -.05 & & & & & & \\
\hline 15 & Conscientiousness & -.07 & 1.02 & -.03 & -.07 & .03 & -.05 & -.07 & -.07 & .01 & .03 & -.09 & .12 & .12 & .06 & .20 & -.07 & & & & & \\
\hline 16 & Openness & -.03 & 1.03 & .04 & -.03 & -.05 & -.06 & .00 & .01 & -.11 & -.02 & -.07 & .10 & .09 & .03 & .27 & .01 & .15 & & & & \\
\hline 17 & Power*Honesty & .00 & .67 & -.22 & -.21 & -.13 & -.15 & .01 & .01 & .07 & .04 & .07 & .08 & .68 & .08 & -.01 & .33 & .08 & .14 & & & \\
\hline 18 & French first language & .77 & .42 & .17 & .13 & .21 & .18 & .03 & .02 & .11 & -.11 & .04 & .20 & .02 & -.10 & .03 & .08 & .03 & -.03 & .00 & & \\
\hline 19 & Age & 21.10 & 1.61 & -.10 & -.14 & -.21 & -.04 & .06 & -.01 & .02 & .05 & -.07 & -.10 & .00 & -.03 & .02 & .00 & -.12 & .04 & .01 & -.21 & \\
\hline & Male & .61 & .49 & .33 & .38 & .44 & .18 & .14 & .14 & .69 & -.21 & .41 & .30 & -.02 & .02 & -.06 & .03 & .01 & -.02 & .04 & .17 & -.06 \\
\hline
\end{tabular}

$N=168$; to provide an indication of significance levels, $r>|.16|, p<.05 ; r>|.20|, p<.01 ; r>|.25|, p<.001$ (note, we used robust estimators for results reported from all estimations); Variable "Male" $(=1$ if male, else $=0)$. French first language $(=1$; else $=0)$. 


\section{Table 6: Latent Growth Curve Estimates (Study 2)}

\begin{tabular}{|c|c|c|c|c|c|c|c|c|}
\hline \multirow[b]{3}{*}{ Predictors } & \multicolumn{4}{|c|}{$\begin{array}{l}\text { Predicting the Latent Intercept } \\
\text { (initial level of antisocial behavior) }\end{array}$} & \multicolumn{4}{|c|}{$\begin{array}{l}\text { Predicting the Latent Slope } \\
\text { (growth in antisocial behavior) }\end{array}$} \\
\hline & \multirow{2}{*}{$\frac{\text { Model } 1}{\text { Estimate }}$} & \multicolumn{2}{|c|}{ Model 2} & \multirow[t]{2}{*}{ Diff. $^{2}$} & \multirow{2}{*}{$\frac{\text { Model } 1}{\text { Estimate }}$} & \multicolumn{2}{|c|}{$\underline{\text { Model } 2}$} & \multirow[t]{2}{*}{ Diff. $^{2}$} \\
\hline & & Estimate & Standard. $\beta$ & & & Estimate & Standard. $\beta$ & \\
\hline Latent Intercept & & & & & $\begin{array}{c}-.07 \\
(1.80)^{*}\end{array}$ & $\begin{array}{c}-.08 \\
(1.87)^{*}\end{array}$ & $\begin{array}{c}-.42 \\
(1.79) *\end{array}$ & 0.00 \\
\hline Behav. selfishness & $\begin{array}{l}3.22 \\
(3.16)^{* * *}\end{array}$ & $\begin{array}{l}3.22 \\
(3.15) * * *\end{array}$ & $\begin{array}{c}.26 \\
(3.56)^{* * * *}\end{array}$ & .01 & $\begin{array}{l}.05 \\
(.18)\end{array}$ & $\begin{array}{c}.05 \\
(.18)\end{array}$ & $\begin{array}{c}.02 \\
(.19)\end{array}$ & 0.00 \\
\hline Game 2 Leader & $\begin{array}{l}-.83 \\
(.85)\end{array}$ & $\begin{array}{l}-.84 \\
(.85)\end{array}$ & $\begin{array}{l}-.07 \\
(.86)\end{array}$ & .01 & $\begin{array}{c}-.49 \\
(1.81)^{*}\end{array}$ & $\begin{array}{c}-.49 \\
(1.80)^{*}\end{array}$ & $\begin{array}{c}-.21 \\
(1.82)^{*}\end{array}$ & 0.00 \\
\hline Power & $\begin{array}{c}1.85 \\
(1.26)\end{array}$ & $\begin{array}{c}1.84 \\
(1.25)\end{array}$ & $\begin{array}{c}.15 \\
(1.25)\end{array}$ & .01 & $\begin{array}{c}.69 \\
(1.89)^{*}\end{array}$ & $\begin{array}{c}.70 \\
(1.94)^{*}\end{array}$ & $\begin{array}{c}.30 \\
(1.99)^{* *}\end{array}$ & 0.02 \\
\hline Testo. $(\mathrm{pg} / \mathrm{mL})^{1}$ & $\begin{array}{c}1.96 \\
(1.51)\end{array}$ & $\begin{array}{c}1.92 \\
(1.47)\end{array}$ & $\begin{array}{c}.19 \\
(1.48)\end{array}$ & .04 & $\begin{array}{c}-.39 \\
(1.30)\end{array}$ & $\begin{array}{c}-.38 \\
(1.27)\end{array}$ & $\begin{array}{c}-.20 \\
(1.25)\end{array}$ & 0.01 \\
\hline Cortisol (ng/mL) & $\begin{array}{l}-.86 \\
(.44)\end{array}$ & $\begin{array}{l}-.83 \\
(.42)\end{array}$ & $\begin{array}{l}-.03 \\
(.42)\end{array}$ & .02 & $\begin{array}{l}-.33 \\
(.68)\end{array}$ & $\begin{array}{l}-.33 \\
(.67)\end{array}$ & $\begin{array}{l}-.06 \\
(.67)\end{array}$ & 0.01 \\
\hline Power*Testo. & $\begin{array}{l}-.27 \\
(.16)\end{array}$ & $\begin{array}{l}-.26 \\
(.15)\end{array}$ & $\begin{array}{l}-.02 \\
(.15)\end{array}$ & .01 & $\begin{array}{c}.92 \\
(2.33)^{* *}\end{array}$ & $\begin{array}{c}.92 \\
(2.32)^{* *}\end{array}$ & $\begin{array}{c}.44 \\
(2.43)^{* *}\end{array}$ & 0.01 \\
\hline Intelligence & $\begin{array}{c}.11 \\
(1.22)\end{array}$ & $\begin{array}{c}.11 \\
(1.19)\end{array}$ & $\begin{array}{c}.09 \\
(1.20)\end{array}$ & .00 & $\begin{array}{l}-.01 \\
(.35)\end{array}$ & $\begin{array}{l}-.01 \\
(.33)\end{array}$ & $\begin{array}{l}-.04 \\
(.33)\end{array}$ & 0.00 \\
\hline Honesty & $\begin{array}{l}-2.11 \\
(2.93) * * *\end{array}$ & $\begin{array}{l}-2.13 \\
(2.94) * * *\end{array}$ & $\begin{array}{c}-.33 \\
(3.19)^{* * *}\end{array}$ & .01 & $\begin{array}{l}-.06 \\
(.32)\end{array}$ & $\begin{array}{l}-.06 \\
(.31)\end{array}$ & $\begin{array}{l}-.05 \\
(.31)\end{array}$ & 0.00 \\
\hline Emotionality & $\begin{array}{l}-.46 \\
(.88)\end{array}$ & $\begin{array}{l}-.46 \\
(.88)\end{array}$ & $\begin{array}{l}-.08 \\
(.89)\end{array}$ & .01 & $\begin{array}{l}-.07 \\
(.48)\end{array}$ & $\begin{array}{l}-.07 \\
(.47)\end{array}$ & $\begin{array}{l}-.06 \\
(.48)\end{array}$ & 0.00 \\
\hline Extraversion & $\begin{array}{l}-.16 \\
(.31)\end{array}$ & $\begin{array}{l}-.15 \\
(.30)\end{array}$ & $\begin{array}{l}-.02 \\
(.30)\end{array}$ & .00 & $\begin{array}{c}.40 \\
(3.25)^{* * *}\end{array}$ & $\begin{array}{c}.39 \\
(3.23)^{* * *}\end{array}$ & $\begin{array}{c}.32 \\
(3.37)^{* * *}\end{array}$ & 0.00 \\
\hline Agreeableness & $\begin{array}{l}-.06 \\
(.12)\end{array}$ & $\begin{array}{l}-.07 \\
(.12)\end{array}$ & $\begin{array}{l}-.01 \\
(.12)\end{array}$ & .00 & $\begin{array}{c}.17 \\
(1.05)\end{array}$ & $\begin{array}{c}.16 \\
(1.04)\end{array}$ & $\begin{array}{c}.14 \\
(1.07)\end{array}$ & 0.00 \\
\hline Conscientiousness & $\begin{array}{l}-.20 \\
(.45)\end{array}$ & $\begin{array}{l}-.20 \\
(.46)\end{array}$ & $\begin{array}{l}-.03 \\
(.46)\end{array}$ & .00 & $\begin{array}{c}.30 \\
(2.27)^{* *}\end{array}$ & $\begin{array}{c}.30 \\
(2.30)^{* *}\end{array}$ & $\begin{array}{c}.27 \\
(2.44)^{* *}\end{array}$ & 0.00 \\
\hline Openness & $\begin{array}{l}.29 \\
(.61)\end{array}$ & $\begin{array}{l}.29 \\
(.60)\end{array}$ & $\begin{array}{c}.05 \\
(.60)\end{array}$ & .01 & $\begin{array}{c}-.42 \\
(2.82)^{* * *}\end{array}$ & $\begin{array}{c}-.42 \\
(2.80) * * *\end{array}$ & $\begin{array}{c}-.38 \\
(3.09)^{* * * *}\end{array}$ & 0.00 \\
\hline Power*Honesty & $\begin{array}{c}.49 \\
(.54)\end{array}$ & $\begin{array}{l}.50 \\
(.55)\end{array}$ & $\begin{array}{c}.05 \\
(.56)\end{array}$ & .01 & $\begin{array}{l}.16 \\
(.55)\end{array}$ & $\begin{array}{c}.15 \\
(.53)\end{array}$ & $\begin{array}{c}.09 \\
(.53)\end{array}$ & 0.01 \\
\hline French language & $\begin{array}{c}.77 \\
(.68)\end{array}$ & $\begin{array}{c}.76 \\
(.68)\end{array}$ & $\begin{array}{c}.05 \\
(.68)\end{array}$ & .00 & $\begin{array}{c}-.47 \\
(1.42)\end{array}$ & $\begin{array}{c}-.47 \\
(1.41)\end{array}$ & $\begin{array}{c}-.17 \\
(1.46)\end{array}$ & 0.01 \\
\hline Age & $\begin{array}{c}-.28 \\
(1.67)^{*}\end{array}$ & $\begin{array}{c}-.28 \\
(1.73)^{*}\end{array}$ & $\begin{array}{c}-.07 \\
(1.72)^{*}\end{array}$ & .00 & $\begin{array}{l}-.19 \\
(2.65)^{* * *}\end{array}$ & $\begin{array}{c}-.19 \\
(2.67)^{* * *}\end{array}$ & $\begin{array}{c}-.27 \\
(2.63)^{* * *}\end{array}$ & 0.00 \\
\hline Male & & $\begin{array}{c}1.85 \\
(1.30)\end{array}$ & $\begin{array}{c}.15 \\
(1.34)\end{array}$ & & & $\begin{array}{c}.85 \\
(2.39)^{* *}\end{array}$ & $\begin{array}{c}.36 \\
(2.39)^{* *}\end{array}$ & \\
\hline
\end{tabular}

Note: Robust $z$-statistics in parentheses; $* * * p<.01 ; * * p<.05 ; * p<.10$. Models estimated with Mplus's robust MLR estimator for categorical dependent variables. Model 1 is estimated using male and female groups separately and constraining estimates to be equal; the model with the constraints was not significantly different from the model without the constraints, $\chi^{2}(32)=37.38, p=$ .24 (Satorra \& Bentler, 2001). Model 2 is estimated using males and females together while controlling for sex differences using the dummy variable "Male" (= 1 if male, else $=0$ ). For Model 2, Wald tests for the significance of the interaction of the variable male with all the variables or only with power, testosterone and the power*testosterone interaction was insignificant, indicating that the parameters for males and females are equivalent. $N=168 .{ }^{1}$ Refers to Time 1 testosterone (to reduce the variance of this measure we divided it by a constant, 100, to move the decimal to the left and hence ensure the convergence of the estimator). ${ }^{2}$ Difference in estimates is between Model 1 and 2 estimates (unstandardized); we report Model 2 results in text. Note, the $r$ squares for the three bounded counts average .90 for Model 1 and .92 for Model 2). 